\title{
Metal-organic chemical vapor deposition enabling all-solid-state Li-ion microbatteries: A short review
}

\author{
Chunguang Chen ${ }^{1,2}$ - R.-A. Eichel ${ }^{2,3}$ P. H. L. Notten ${ }^{1,2}$
}

Received: 14 December 2016 / Accepted: 9 May 2017 / Published online: 27 June 2017

(C) The Author(s) 2017. This article is an open access publication

\begin{abstract}
For powering small-sized electronic devices, allsolid-state Li-ion batteries are the most promising candidates due to its safety and allowing miniaturization. Thin film deposition methods can be used for building new all-solid-state architectures. Well-known deposition methods are sputter deposition, pulsed laser deposition, sol-gel deposition, atomic layer deposition, etc. This review summarizes thin film storage materials deposited by metal-organic chemical vapor deposition (MOCVD) for all-solid-state Li-ion batteries. The deposition parameters strongly influence the quality of the films, such as surface morphology, composition, electrochemical stability and cycling performance. Some materials have been successfully deposited by MOCVD into 3D-structured substrates, revealing conformal, homogeneous and high performance battery properties.
\end{abstract}

Keywords All-solid-state $\cdot$ Three dimension $\cdot$ Lithium-ions batteries $\cdot$ Metal-organic chemical vapor deposition $\cdot$ Thin film

\section{Introduction}

Numerous miniaturized autonomous devices, such as small medical implants, hearing aids, integrated lighting solutions and many others are nowadays emerging, thereby improving the quality of our life [1]. High level integration is required

P. H. L. Notten

p.h.1.notten@tue.nl

1 Eindhoven University of Technology, P.O. Box 513, 5600, MB Eindhoven, The Netherlands

2 Forschungszentrum Jülich (IEK-9), D-52425 Jülich, Germany

3 RWTH Aachen University, D-52074 Aachen, Germany since most of these devices are restricted to a volume scale of $1-10 \mathrm{~mm}^{3}$. In response to this, small on-board power suppliers are urgently required. Lithium-ion batteries (LIBs) advantageously combine low-cost, high energy density with environmental friendliness, and have therefore been long considered as the most promising candidates to power electronic devices $[2,3]$. The vast majority of LIBs are applying liquid organic solvents containing Li salts as electrolytes. This generates some serious safety concerns as these liquid electrolytes are combustible and may lead to potentially dangerous leakage risks [4]. Moreover, separators used in conventionally liquid-based LIBs further increases the volumetric energy density, which is not compatible with miniaturization.

In this regards, the concept of all-solid-state micro-batteries has been proposed [5-7]. The all-solid-state architecture was firstly proposed in 1972, on the basis of metallic lithium anodes, (doped) lithium iodide solid-state electrolytes and a metal-iodide based cathode [8]. Since then all-solid-state LIBs were widely investigated. Advantages of the all-solidstate architecture are, on the one hand, offering more flexibility in the design facilitating miniaturization and, on the other hand, enhancing safety due to the avoidance of electrolyte decomposition and leakage.

Many methods have been described to deposit the thin film LIBs. Based on the deposition rate, these methods can be divided into two groups: (i) fast deposition rate methods such as pulsed laser deposition, sputter deposition and E-beam evaporation and (ii) slow rate methods, including metalorganic chemical vapor deposition (MOCVD) and atomic layer deposition (ALD). In general for methods in the former class, there is a temperature difference between the substrate and the deposited films, which may lead to thermal tensile stress and disadvantageously may cause film cracking. ALD is a novel method, by which high quality thin films can be deposited. This method has therefore been intensively used for 
the deposition of photovoltaics thin films $[9,10]$. Regrettably the deposition rate of ALD is too slow and this method is
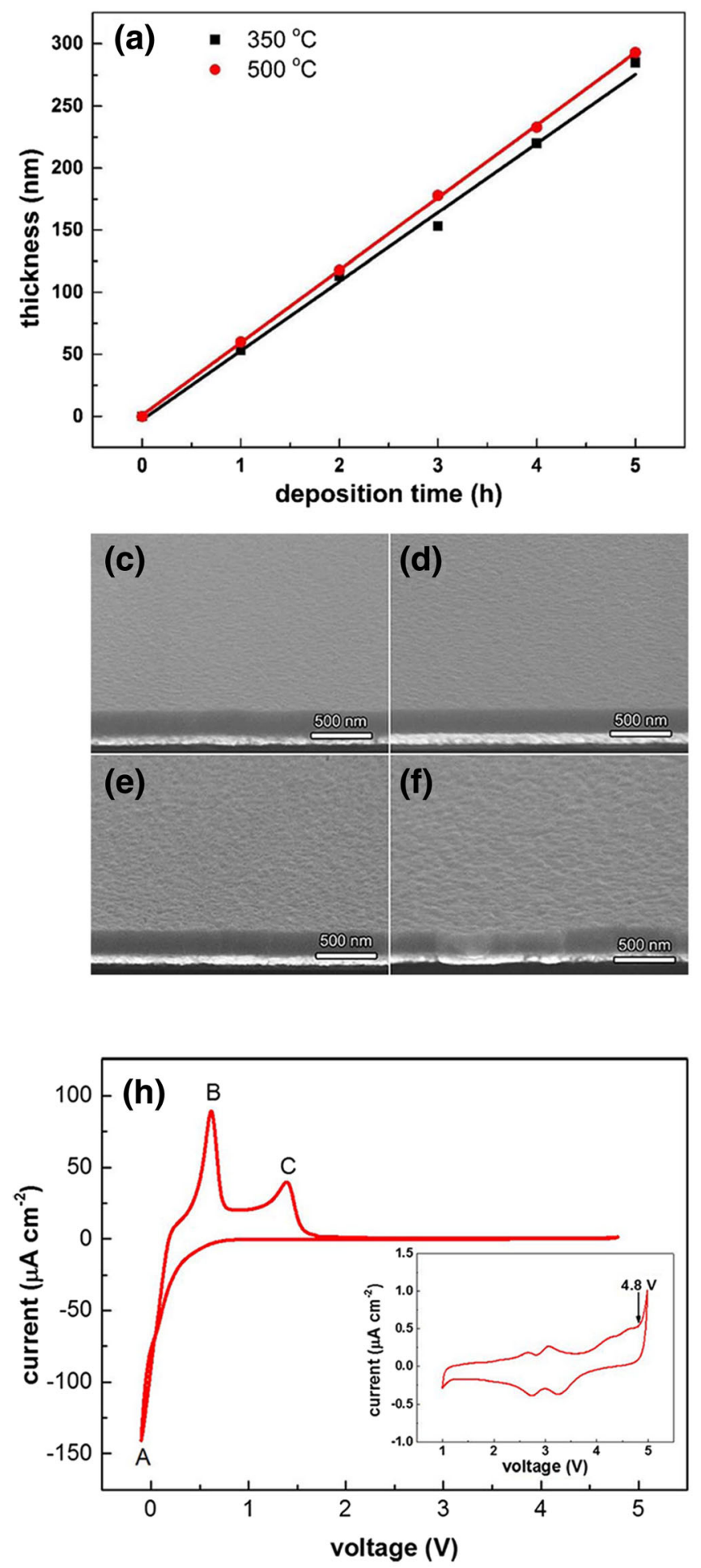

Fig. 1 Deposited film thickness as a function of deposition time at $350{ }^{\circ} \mathrm{C}$ and $500{ }^{\circ} \mathrm{C}$ (a) and Arrhenius plot for the deposition rate of $\mathrm{Li}_{3} \mathrm{PO}_{4}$ films (b). SEM images of $\mathrm{Li}_{3} \mathrm{PO}_{4}$ thin films deposited at different temperatures $300{ }^{\circ} \mathrm{C}(\mathbf{c}), 350{ }^{\circ} \mathrm{C}(\mathbf{d}), 400{ }^{\circ} \mathrm{C}(\mathbf{e}), 450{ }^{\circ} \mathrm{C}(\mathbf{f})$ therefore not competitive in the large-scale production electrochemical storage devices [11]. MOCVD can be
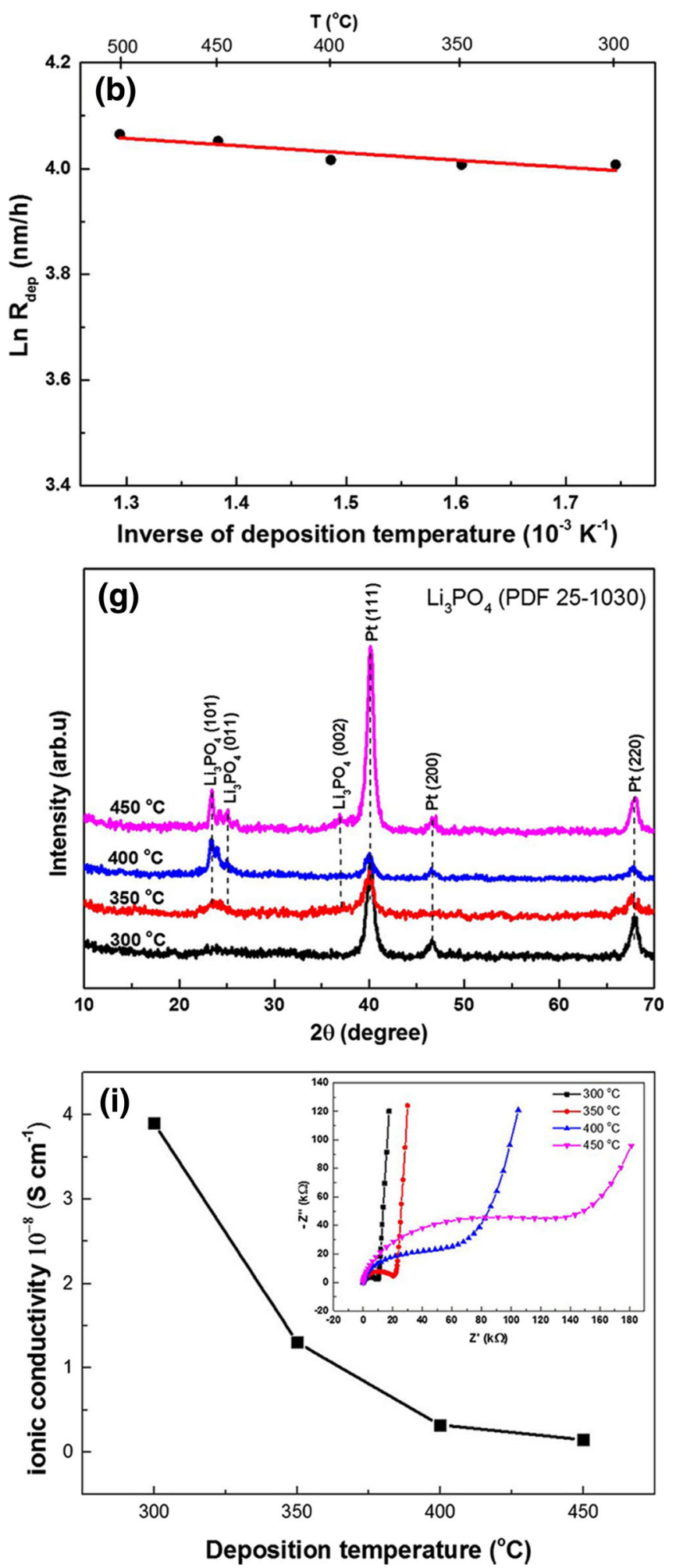

and XRD patterns (g). Cyclic voltammogram of a $\mathrm{Pt} / \mathrm{Li}_{3} \mathrm{PO}_{4} / \mathrm{Li}$ half-cell at room temperature (h) and ionic conductivity of $\mathrm{Li}_{3} \mathrm{PO}_{4}$ films as a function of deposition temperature (i). Reproduced with permission [47]. Copyright 2015, The Electrochemical Society 
characterized by a medium deposition rate, leading to highly step-conformal and homogenous thin films. Moreover, low pressure chemical vapor deposition (LPCVD) has the advantage to provide excellent stoichiometry control of the deposited films.

Recently several reviews have been written to highlight the research on solid-state microbatteries. These publications present a nice overview on novel materials, advanced synthesis technologies and characterization methods [11-18]. The present review focuses on the MOCVD deposition of materials for thin film all-solid-state LIBs and the three dimensional (3D) all-solid-state LIBs.

\section{Deposition of thin film-based materials for all-solid-state LIBs}

Several thin film-based materials have been deposited by MOCVD, including solid electrolytes, anode and cathode materials. Attention will be focused on the influence of the deposition parameters on the crystallinity, morphology, electrochemical stability and cycling performance of these materials.

\subsection{Solid-state electrolytes}

To build all-solid-state LIBs, solid electrolytes are obviously a key component. Compared to their liquid counterparts, solid electrolytes offer several unique characteristics which can be highlighted as follows:

(i) Solid electrolytes, especially the inorganic materials, are stable at elevated temperatures. Their conductivity increases with increasing temperature and the conductivity of some solid-state electrolytes may even be comparable to that of liquid electrolytes [18].

(ii) Undesirable "cross-talk" effects between the cathode and anode can, in some systems, be greatly suppressed or even avoided. For example, in lithium-sulfur batteries which are based on liquid organic electrolytes, the maligned polysulide "shuttle effect" will drastically lower the columbic efficiency [19]. These issues can be addressed by solid-state electrolytes as these undesirable species or intermediates cannot be dissolved and transported in these media [18].

(iii) Solid-state electrolytes are chemically more stable when coupled with high voltage Li cathodes. High electrochemical decomposition voltages of about $6 \mathrm{~V}$ vs metallic Li have been reported. The standard lithium reference electrode that will be used to define the voltages throughout this review [20].

(iv) Lithium dendrites formation can be restrained, which allows the use of metallic lithium as anode due to the mechanically more robust nature of solid-state electrolytes.
Fig. 2 Deposition rate for $\mathrm{Li}_{\mathrm{x}} \mathrm{Ta}_{\mathrm{y}} \mathrm{O}_{\mathrm{z}}$ determined by RBS as a function of the susceptor temperature during deposition (a); Lithium-to-tantalum ratio (determined by ICP-AES) and the oxygen-to-tantalum ratio of (determined by RBS) for samples deposited at various susceptor temperatures (b). Cyclic Voltammetry of $\mathrm{LiTaO}_{3}$ films deposited at various susceptor temperatures (c). Reproduced with permission from ref. [52]
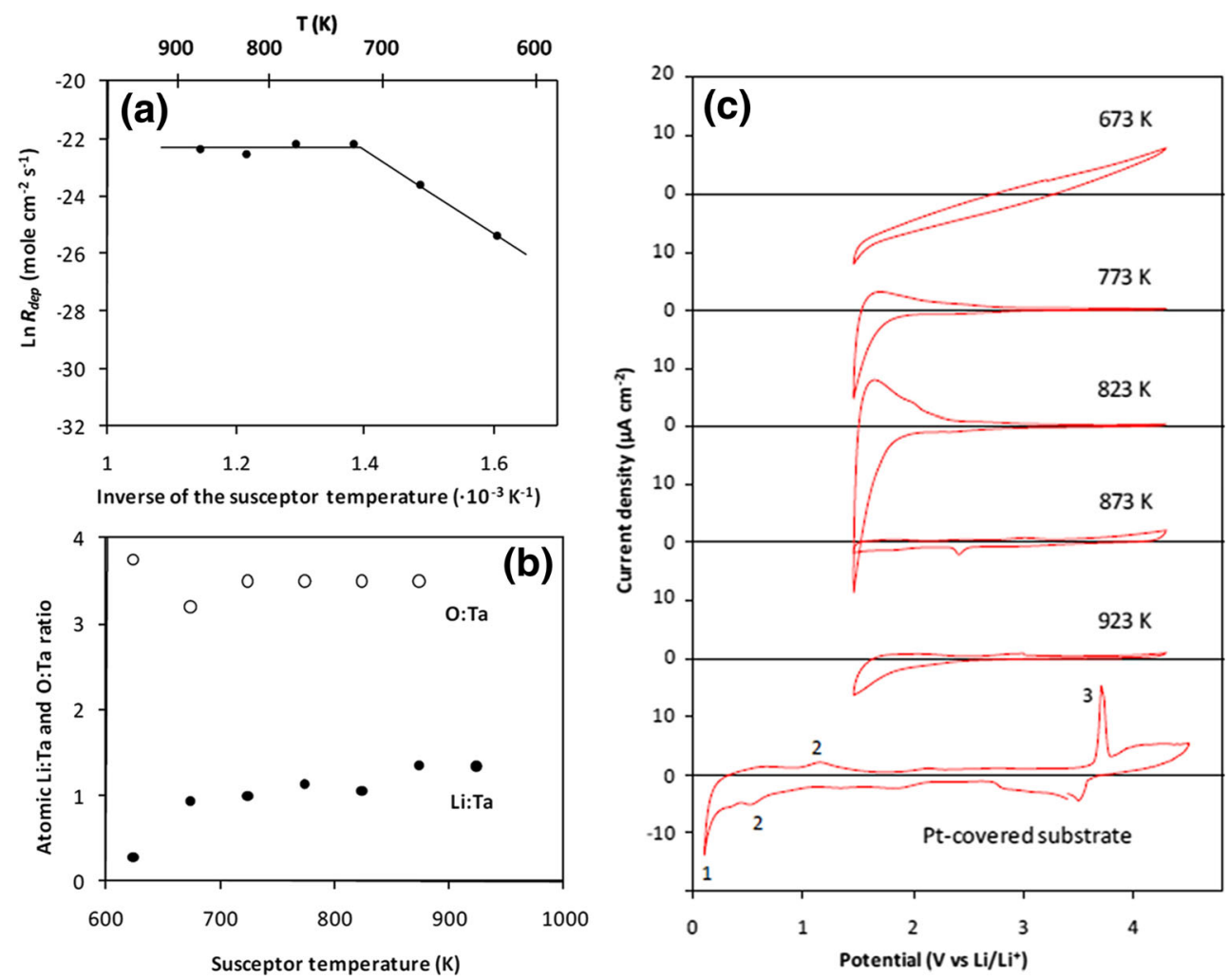
Inorganic ceramics and polymers are two major solid electrolyte systems which have been widely investigated for allsolid-state architectures. Examples are thiophosphates and complex sulfides, such as $\mathrm{Li}_{3} \mathrm{PS}_{4}[21,22], \mathrm{Li}_{7} \mathrm{P}_{3} \mathrm{~S}_{11}$ [23-25], and $\mathrm{Li}_{10} \mathrm{GeP}_{2} \mathrm{~S}_{12}$ [26-28], polymeric Li-ion conductors [12, 29], (nitrogen doped) lithium phosphate $\left(\mathrm{Li}_{3} \mathrm{PO}_{4}\right.$ and $\left.\mathrm{LiPON}\right)$ [30-32] and $\mathrm{MeO}-$ based oxides $\left(\mathrm{LiNbO}_{3}\right.$ [33], $\mathrm{LiTaO}_{3}$ [34] and Garnets-type $\mathrm{Li}_{7} \mathrm{La}_{3} \mathrm{Zr}_{2} \mathrm{O}_{12}$ [35-37]). Generally, lithium thiophosphates and complex sulfides have a moisture sensitive nature. Once absorbing water, $\mathrm{H}_{2} \mathrm{~S}$ will be formed, which is not safe during materials preparation and cell integration. In a laboratory environment, the synthesis and characterization of these chemicals are usually performed in Argon-filled gloveboxes. However, this is not very compatible with largescale industrial production and, consequently, these Sulphurbased systems did hardly enter the mass production market. Polymer-based electrolytes, on the other hand, seem to be a better choice in this respect as the elastic nature of polymers can endure the volumetric changes caused by (dis)charging and outside pressures. However, this class of electrolytes usually have a very low ionic conductivity at room-temperature. To achieve a more reasonable conductivity, elevated temperatures above $80{ }^{\circ} \mathrm{C}$ are necessary [18]. Moreover, most electrolytes are so-called "hybrid" systems due to the presence of liquid organic solvents, which will also introduce some safety issues, such as solvent leakage, combustible risk, and small-size designing problems $[38,39]$. Therefore, polymerbased electrolytes are also not very attractive for practical use of small-sized Li-ion batteries.

To compensate the disadvantages and problems encountered by thiophosphates and polymer electrolytes, new solidstate electrolytes have been proposed and a well-known example is $\mathrm{Li}_{3} \mathrm{PO}_{4}$. $\mathrm{Li}_{3} \mathrm{PO}_{4}$ has been widely used by many commercial all-solid-state battery manufacturers due to the relatively high Li-ion conductivity and (electro)chemical stability with respect to metallic $\mathrm{Li}$ anodes [40]. Some methods have been described to deposit thin films of $\mathrm{Li}_{3} \mathrm{PO}_{4}$, including pulsed laser deposition [41, 42], atomic layer deposition (ALD) [43], E-beam evaporation [44] and sputter deposition [45, 46]
Fig. 3 XRD patterns (a), CVs of $\mathrm{LiCoO}_{2}$ layers obtained at varying temperatures $(\mathbf{b})$ and SEM images $(\mathbf{c}-\mathbf{f})$ of $\mathrm{LiCoO}_{2}$ thin films deposited at various temperatures. Reproduced with permission [58]. Copyright 2009, The Electrochemical Society

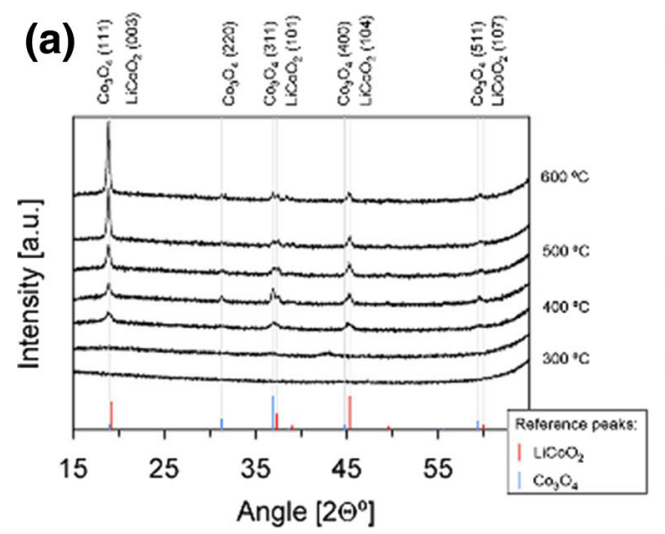

(b)
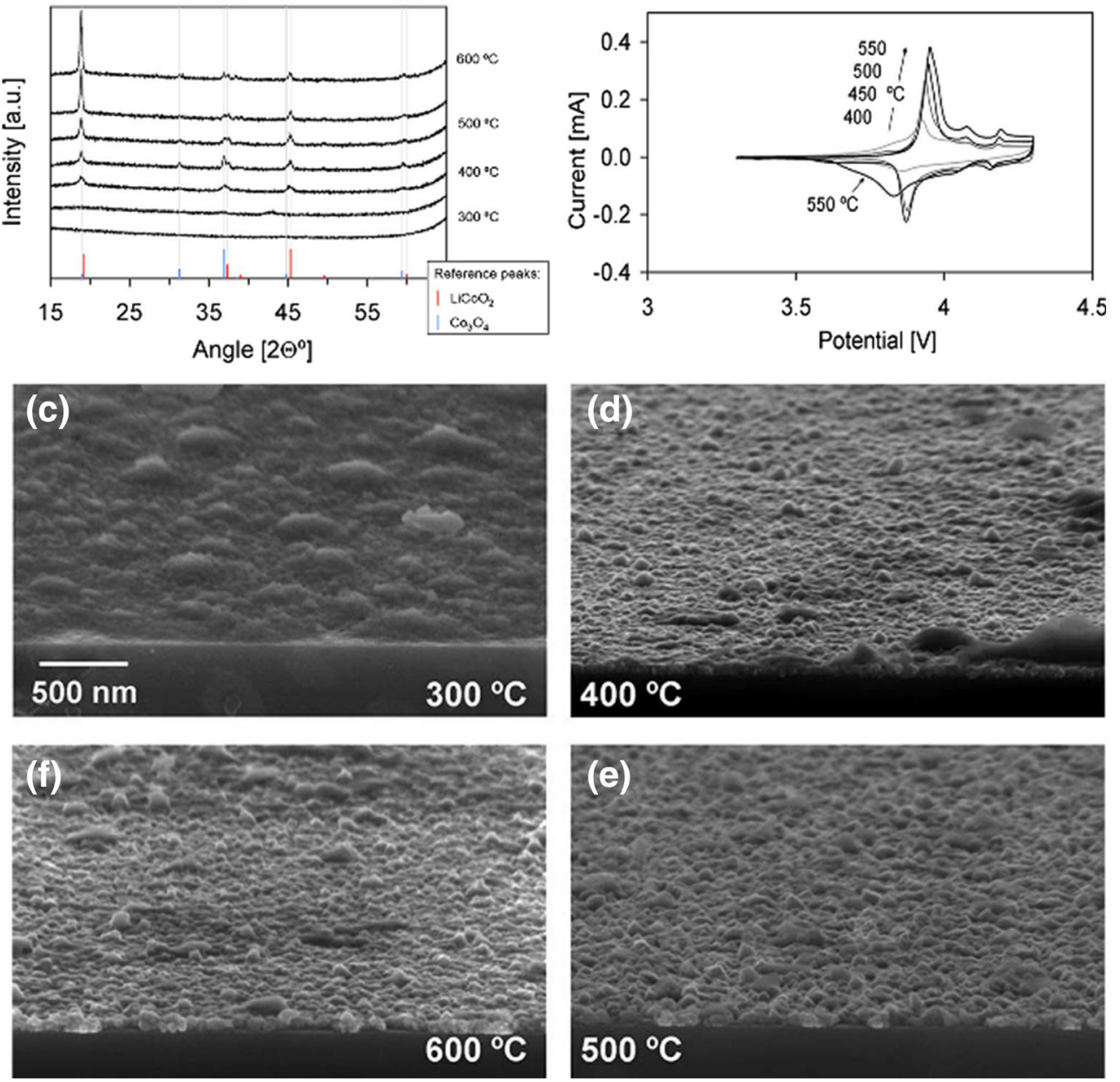
Figure 1(a) shows the deposition thickness of $\mathrm{Li}_{3} \mathrm{PO}_{4}$ thin films as a function of time at different temperatures by MOCVD, using tert-butyllithium (t-BuLi) as Li-precursor and trimethyl phosphate(TMPO) as P-precursor [47]. The deposition rate can be obtained from the slopes of these lines and is constant at both temperatures, which is crucial for obtaining high quality and homogeneous thin films. From the deposition rate as a function of temperature, an Arrhenius plot $\left(\ln R_{\text {dep }}\right.$ Vs. 1/T in Fig. 1(b)) can be constructed. The activation energy of the deposition process can be calculated from the slope of this line and is calculated, in this example, to be $1.14 \mathrm{~kJ} / \mathrm{mol}$. This low activation energy suggests a diffusion-controlled deposition process in the investigated temperature range.

Figure $1(\mathrm{c}-\mathrm{f})$ shows the morphology of the $\mathrm{Li}_{3} \mathrm{PO}_{4}$ thin films deposited by MOCVD at different temperatures, indicating the homogeneous quality without revealing any cracks or pinhole defects. When deposing at elevated temperatures, it is clear that the surface textile becomes somewhat rougher. It is known that the $\mathrm{Li}_{3} \mathrm{PO}_{4}$ films deposited at lower temperatures are not crystalline but has become amorphous. Increasing the deposition temperature led to complete crystallization of the deposited films. The XRD patterns shown in Fig. 1(g) confirm the influence of the deposition temperature on the crystallography.

The electrochemical stability has been investigated by cyclovoltammography $(\mathrm{CV})$. The results are shown in Fig. 1(h) and suggest that the deposited $\mathrm{Li}_{3} \mathrm{PO}_{4}$ films are electrochemically stable in the voltage range of 0 to $4.7 \mathrm{~V}$ vs $\mathrm{Li}$ / $\mathrm{Li}^{+}$. Electrochemical impedance spectroscopy (see the inset of Fig. 1(i)) has been carried out to confirm that the amorphous $\mathrm{Li}_{3} \mathrm{PO}_{4}$ has a better ionic conductivity than the crystallized form. The $\mathrm{Li}_{3} \mathrm{PO}_{4}$ films deposited at $300{ }^{\circ} \mathrm{C}$ yielded the highest ionic conductivity at room temperature of 3.9 . $10^{-8} \mathrm{~S} \cdot \mathrm{cm}^{-1}$.

$\mathrm{LiTaO}_{3}$ has received much attention due to their favorable optical and electrical properties. Thin film preparation methods, such as sol-gel deposition [48], pulsed laser deposition [49], ALD [50] and sputter deposition [51], are usually
Fig. 4 XRD patterns of $\mathrm{Co}_{3} \mathrm{O}_{4}$ thin films deposited at $623 \mathrm{~K}$ with increasing oxygen flow (a), Arrhenius plot revealing the deposition rate of $\mathrm{Co}_{3} \mathrm{O}_{4}$ at various temperatures: the oxygen flow was set at $50 \mathrm{sccm}$ (spheres) or $1 \mathrm{sccm}$ (crosses) (b) and crosssection SEM images of $\mathrm{Co}_{3} \mathrm{O}_{4}$ films deposited at $623 \mathrm{~K}$ at various oxygen flow rates $(\mathbf{c}-\mathbf{f})$. Reproduced with permission from ref. [52]
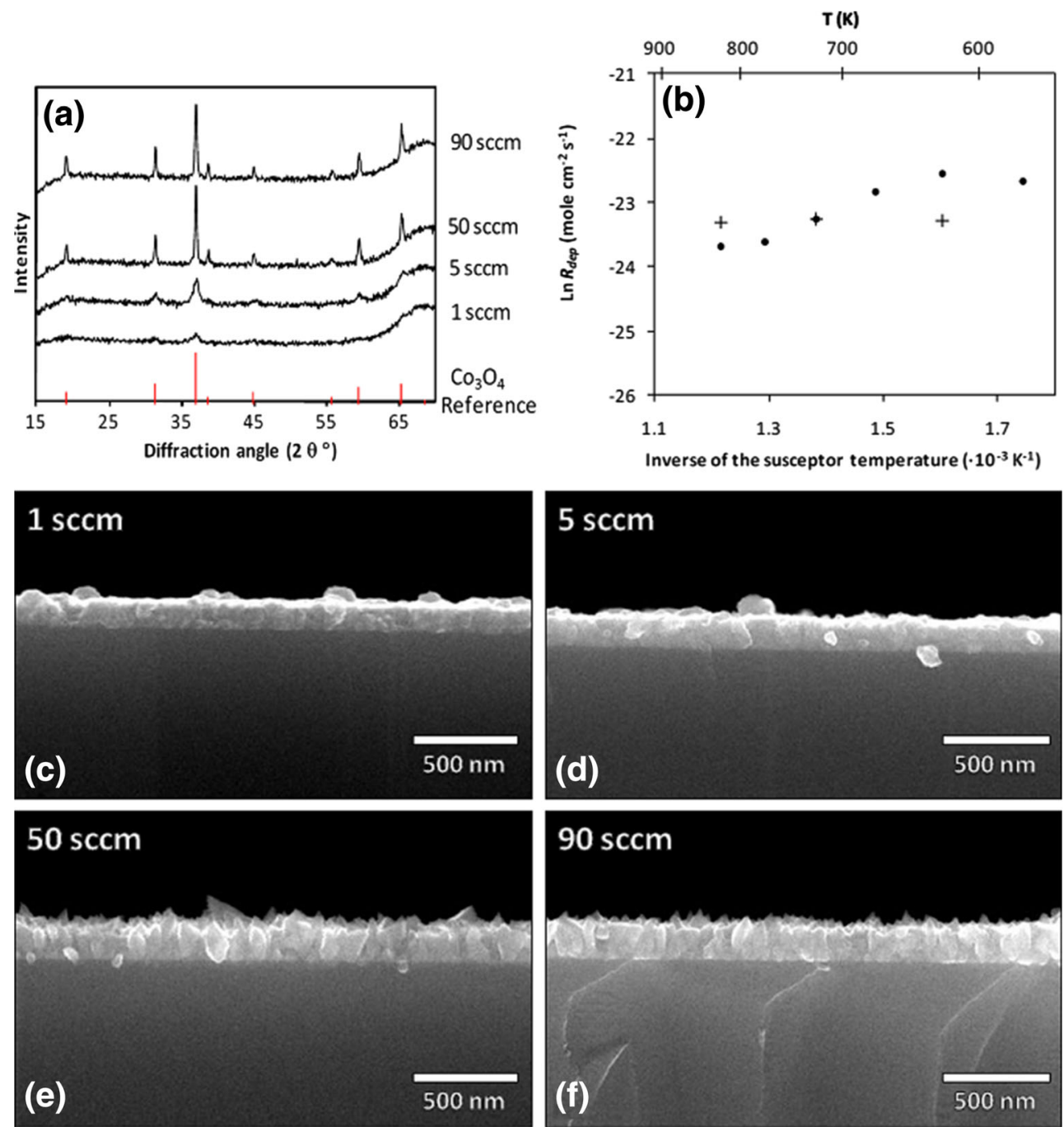
applied for the synthesis of $\mathrm{LiTaO}_{3}$ thin films. $\mathrm{LiTaO}_{3}$ was also investigated by MOCVD, using t-BuLi and tantalum(V)ethoxide as precursors. As shown in the Arrhenius plot in Fig. 2(a), the deposition rate of $\mathrm{Li}_{\mathrm{x}} \mathrm{Ta}_{\mathrm{y}} \mathrm{O}_{\mathrm{z}}$ strongly depends on the deposition temperature [52]. Also in this case it was concluded that deposition at high temperatures was diffusion controlled ( $>723 \mathrm{~K}$ ), while the deposition at low temperatures was reaction rate controlled as has been concluded from the higher slope in the Arrhenius plot [52]. The chemical composition of the films has been analyzed. Rutherford backscattering spectrometry (RBS) and inductively coupled plasma-atomic emission spectroscopy (ICP-AES) results are shown in Fig. 2(b) and indicate that the deposition temperature only has a weak effect on the film composition. However, the CV spectra of the various films, shown in Fig. 2(c), reveal that the deposition temperature has a very pronounced effect on the voltage stability window.

\subsection{Cathode materials}

Cathode materials are of significant importance as the theoretical capacity of LIBs stack is highly dependent on these materials. Since it was firstly synthesized by
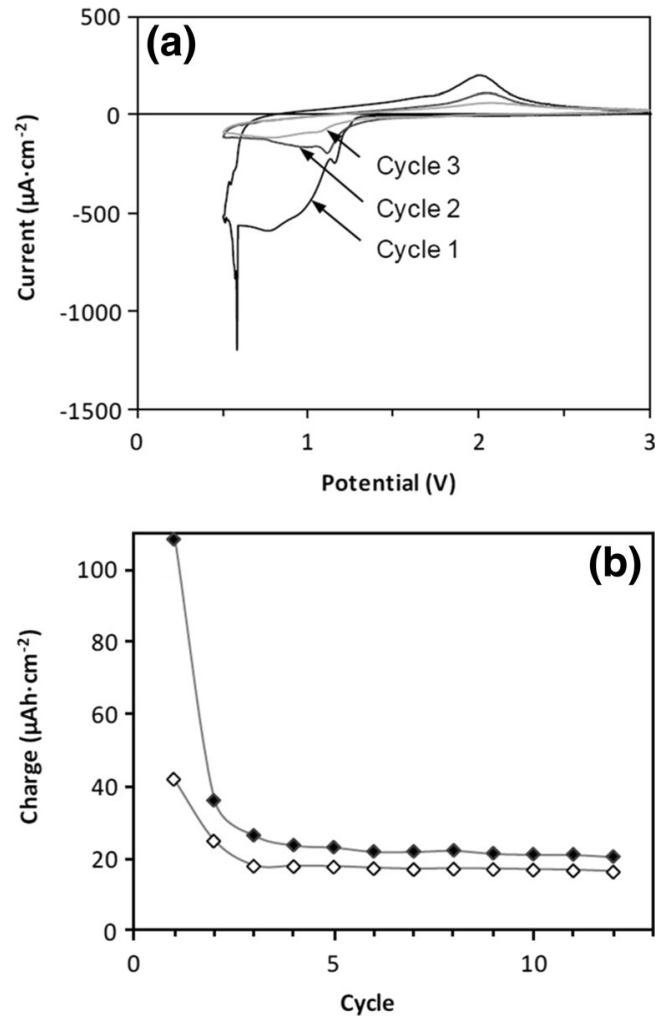

Fig. $5 \mathrm{CV}$ cycle 1,2 and 3 at the $1 \mathrm{mV} \cdot \mathrm{s}^{-1}$ of $\mathrm{a} \mathrm{Co}_{3} \mathrm{O}_{4}$ film (a). The thin film was deposited at $773 \mathrm{~K}$ and the charge capacity of the electrode was based on CVs (b): the black diamonds indicate the charge involved in the reduction (lithiation) reaction while the white symbols represent that of the oxidation reaction. The figure is based on Ref.[52]
Johnston et al. in 1958, $\mathrm{LiCoO}_{2}$ has been extensively investigated as cathode material. [53] Due to the high theoretical capacity of $274 \mathrm{mAh} / \mathrm{g}$ and stable (de)lithiation structure, $\mathrm{LiCoO}_{2}$ is also widely used in commercial, liquid-based, LIBs. In general, $\mathrm{LiCoO}_{2}$ have two crystal structures: the spinel, low temperature, phase $\left(\mathrm{LT}-\mathrm{LiCoO}_{2}\right.$ ) and the high temperature layered hexagonal structure $\left(\mathrm{HT}-\mathrm{LiCoO}_{2}\right)$. Various methods have been described to deposit electrochemically active $\mathrm{LiCoO}_{2}$ thin films, including sol-gel methods $[54,55]$, radio frequency (RF)-magnetron sputtering [55-57], and pulsed laser deposition [57].

MOCVD was also employed to deposit $\mathrm{LiCoO}_{2}$ thin films with t-BuLi as Li-precursor and $\mathrm{CpCo}(\mathrm{CO})_{2}$ as Co-precursor. As expected, the XRD patterns shown in Fig. 3(a) indicate that the crystallography of the deposited $\mathrm{LiCoO}_{2}$ layers are strongly dependent on the deposition temperature [58]. No crystalline phases are detected for the samples deposited at $300{ }^{\circ} \mathrm{C}$, the material is fully amorphous. The degree of crystallinity strongly increases at higher deposition temperature. However, it is hard to distinguish between the HT-LiCoO 2 and LT-
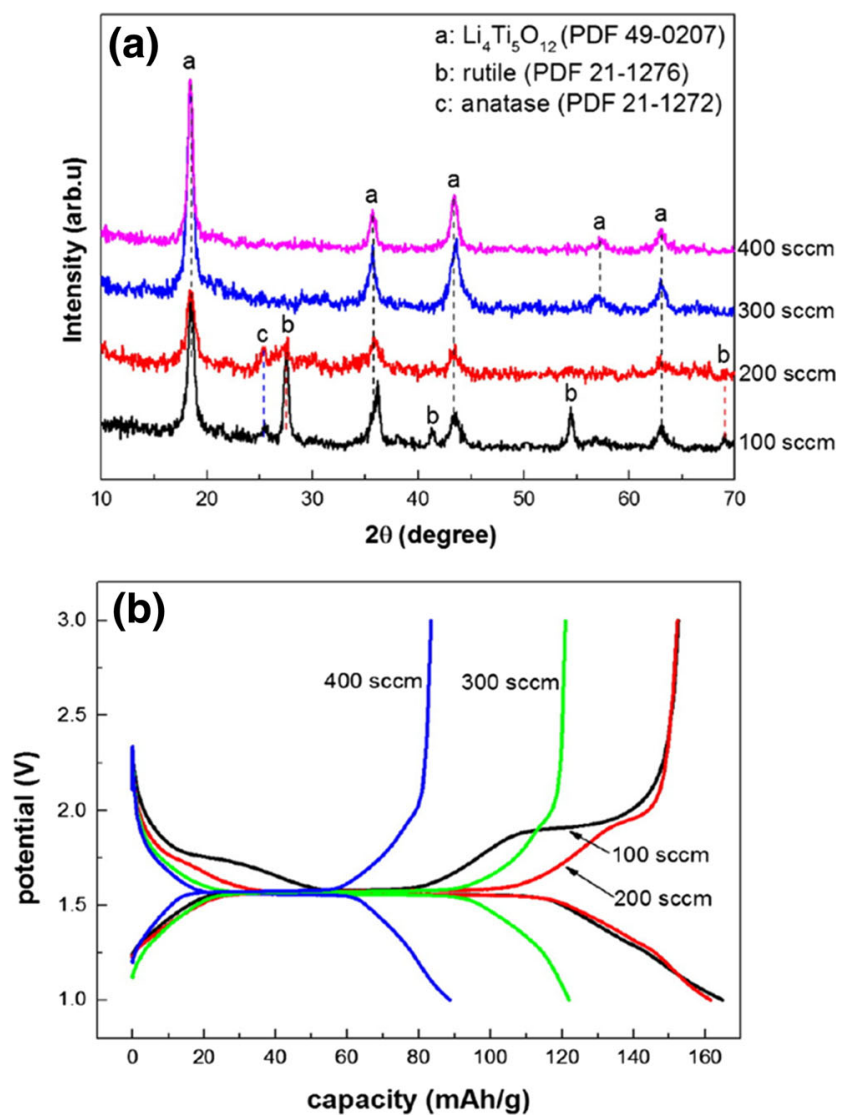

Fig. 6 XRD patterns and charge/discharge voltage profiles of $\mathrm{Li}_{4} \mathrm{Ti}_{5} \mathrm{O}_{12}$ thin films deposited with various Li-precursor flow rates and fixed oxygen and titanium precursor flow rates. Reproduced with permission [69]. Copyright 2016, Elsevier 
$\mathrm{LiCoO}_{2}$ since their diffractions are highly overlapping in the XRD patterns. SEM observations confirm the influence of the deposition temperature on the
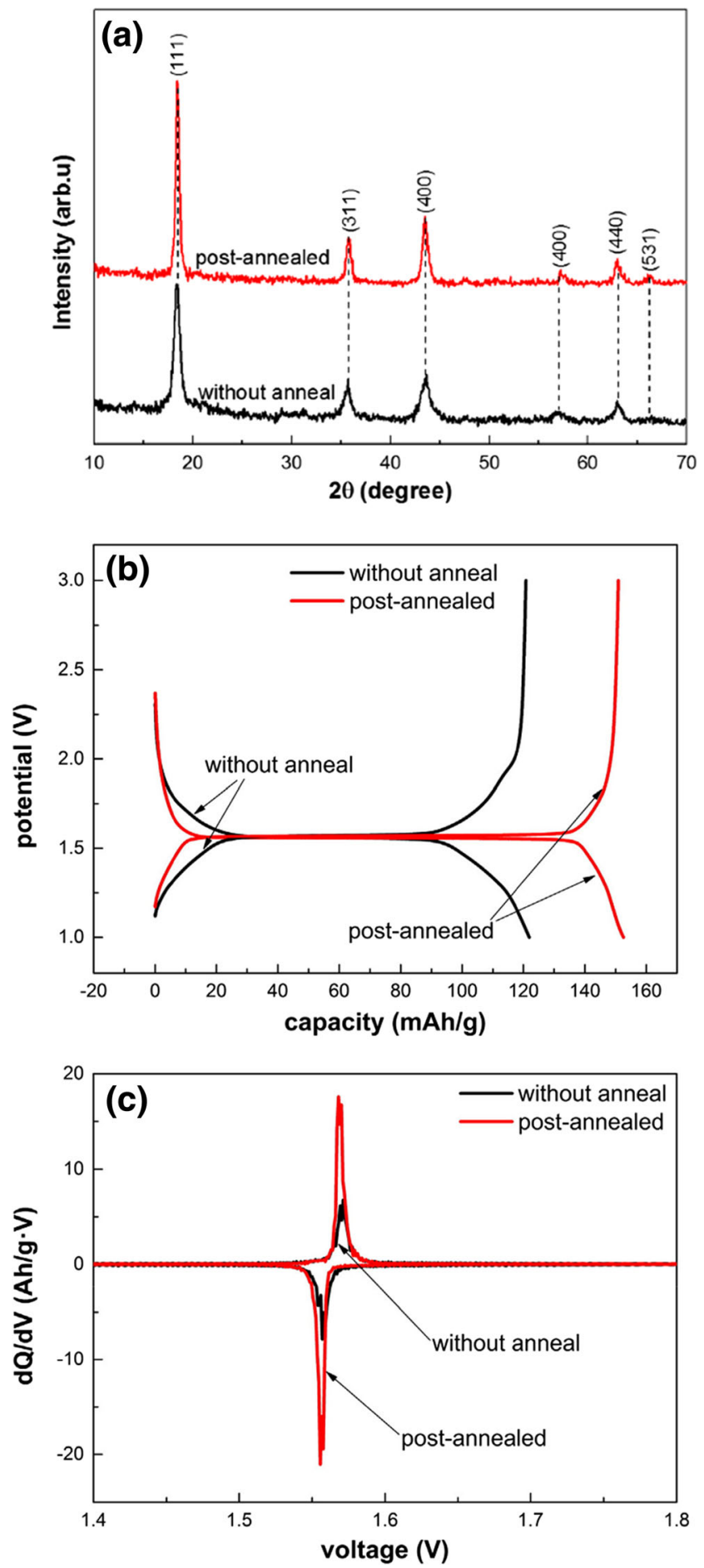

Fig. 7 XRD patterns of $\mathrm{Li}_{4} \mathrm{Ti}_{5} \mathrm{O}_{12}$ films (deposited with $1 \mathrm{sccm} \mathrm{O}, 300$ sccm Li and $200 \mathrm{sccm}$ Ti-precursor flow rates) with and without postannealing (a). Voltage curves (b) and derivative of the storage capacity with respect to voltage curves (c) of $\mathrm{Li}_{4} \mathrm{Ti}_{5} \mathrm{O}_{12}$ films with (red curve) and without (black curve) post-annealing. Reproduced with permission [69]. Copyright 2016, Elsevier microstructure, as shown in Fig. 3(c-f). Clearly, it can be seen that the $300{ }^{\circ} \mathrm{C}$ deposited film has an amorphous morphology with a rough surface. Deposition at higher temperatures gives rise to more homogeneous
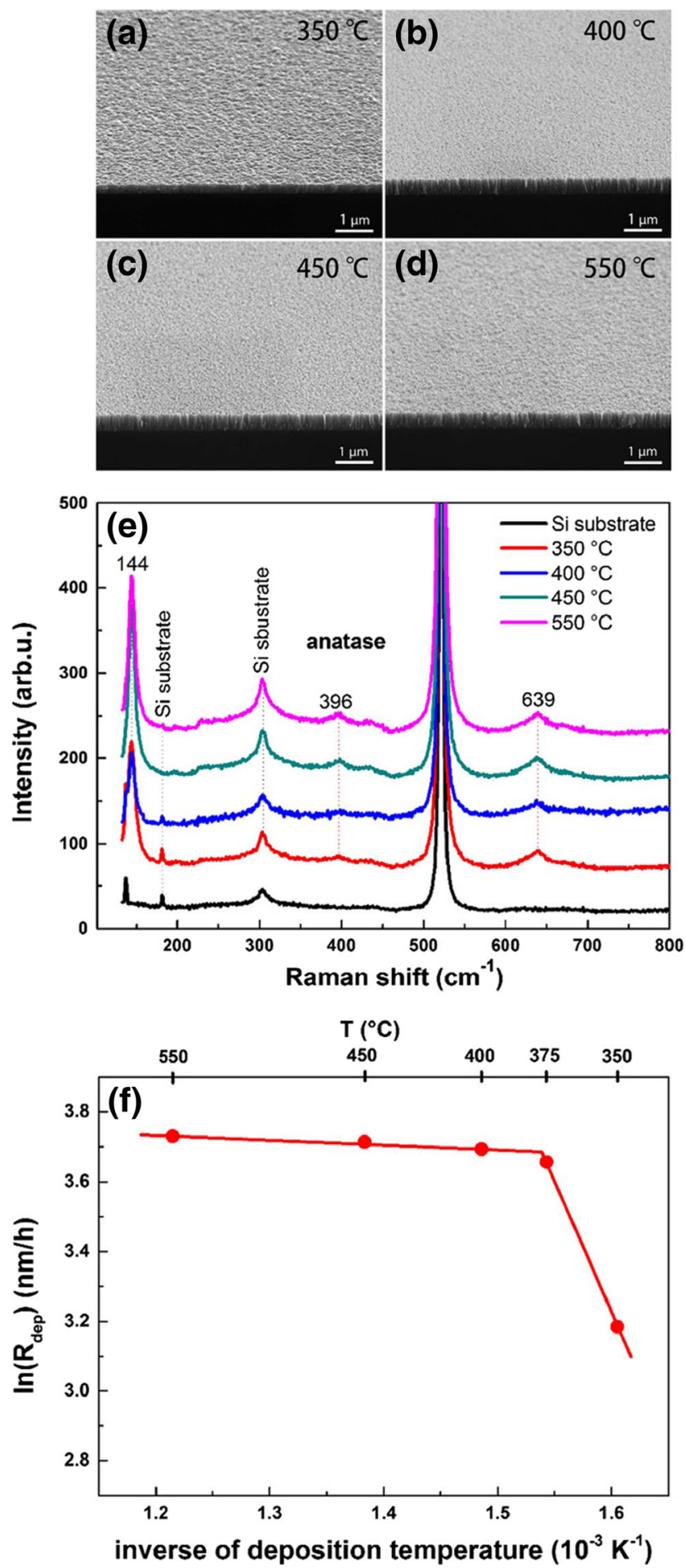

Fig. 8 SEM images (a), Raman spectra (b) and Arrhenius plot (c) of $\mathrm{TiO}_{2}$ films deposited at various temperatures. Reproduced with permission [76]. Copyright 2016, The Electrochemical Society 
and crystalline structures. In order to investigate the electrochemical activity of the thin film electrodes deposited at various temperatures, CV measurements has been reported which are shown in Fig. 3(b). Obviously, it can be concluded that the electrodes deposited at low temperatures are hardly electrochemically active. Calculated from the integral charge, the samples obtained at $500{ }^{\circ} \mathrm{C}$ are most active and deliver the highest storage capacity. This $\mathrm{CV}$ fingerprint resembles that of $\mathrm{LiCoO}_{2}$ powders [59].

Thackeray et al. reported in 1985 that $\mathrm{Co}_{3} \mathrm{O}_{4}$ can also be used as electrode material [60]. $\mathrm{Co}_{3} \mathrm{O}_{4}$ was intensively investigated for the feasibility in LIBs. The electrochemical reaction scheme of $\mathrm{Co}_{3} \mathrm{O}_{4}$ upon (de)lithiation follows a two steps mechanism [61].

$$
\begin{aligned}
& 8 \mathrm{Li}^{+}+\mathrm{Co}_{3} \mathrm{O}_{4}+8 e^{-} \rightarrow 4 \mathrm{Li}_{2} \mathrm{O}+3 \mathrm{Co} \\
& \mathrm{Co}+\mathrm{Li}_{2} \mathrm{O} \leftrightarrow 2 \mathrm{Li}^{+}+\mathrm{CoO}+2 e^{-}
\end{aligned}
$$

The first step was considered not completely irreversible, which will effectively consume and fix a quarter of available lithium in the Li-ion battery system. It was proposed that the $\mathrm{Co}_{3} \mathrm{O}_{4}$ electrode can only be cycled in the second step.

It has been demonstrated that high quality $\mathrm{LiCoO}_{2}$ can be deposited by MOCVD [52]. Without involving the Li-precursor during the MOCVD deposition process, there is a possibility to synthesize $\mathrm{Co}_{3} \mathrm{O}_{4}$ films by making use of the Co-precursor only. $\mathrm{Co}_{3} \mathrm{O}_{4}$ thin films have also been deposited by MOCVD [52]. In contrast to the MOCVD deposition of $\mathrm{LiCoO}_{2}$, the oxygen flow plays an important role in the deposition of $\mathrm{Co}_{3} \mathrm{O}_{4}$ thin films. The XRD patterns of Fig. 4(a) shows that increasing the oxygen flow rate at the fixed temperature of, for example, $623 \mathrm{~K}$ is very beneficial to obtain well-crystallized thin films. The SEM observations of Fig. 4(c-f) also confirm the influence of oxygen flow rate. At higher flow rates, the deposited thin films have a higher degree of crystallinity as can be recognized on the sharp edges leaving the electrode surface. On the other hand, at low flow-rate samples, the surfaces are smoother.

The influence of the temperature was also investigated with a fixed oxygen flow rate of $50 \mathrm{sccm}$ [52]. Remarkably, there is a clear trend that the deposition rate will decrease with increasing temperature (see spheres in Fig. 4(b)). This is contradictory to the previous observations for $\mathrm{Li}_{3} \mathrm{PO}_{4}, \mathrm{LiTaO}_{3}, \mathrm{Li}_{4} \mathrm{Ti}_{5} \mathrm{O}_{12}$, $\mathrm{LiCoO}_{2}$, where increasing temperatures enhance the deposition rate. The decrease in the present $\mathrm{Co}_{3} \mathrm{O}_{4}$ case has been explained by depletion of the precursor as $\mathrm{Co}_{3} \mathrm{O}_{4}$ has already been deposited on the susceptor surface before reaching the substrates. To confirm this, a lower oxygen flow rate of $1 \mathrm{sccm}$ was selected for the deposition at some temperatures. As displayed by the crosses in Fig. 4(b), it can be seen the deposition rate at low oxygen flow rate is temperature independent. This indeed demonstrated that there is a precursor deficiency at higher temperatures, resulting from some undesirable reactions, which can be limited by decreasing the concentration of the oxygen reactive gas.

The electrochemical response (Fig. 5(a)) of a $\mathrm{Co}_{3} \mathrm{O}_{4}$ electrode, deposited at $673 \mathrm{~K}$ with $3 \mathrm{sccm}$ of $\mathrm{O}_{2}$, was investigated by $\mathrm{CV}$. The results show that there is a large deviation of the first cycle from the subsequent cycles. After the first reduction/oxidation cycle the currents are highly reduced due to the irreversible reaction. After the second cycle, the reversibility has increased, revealing the high storage activity of the deposited thin films. The integrated storage capacity is shown in
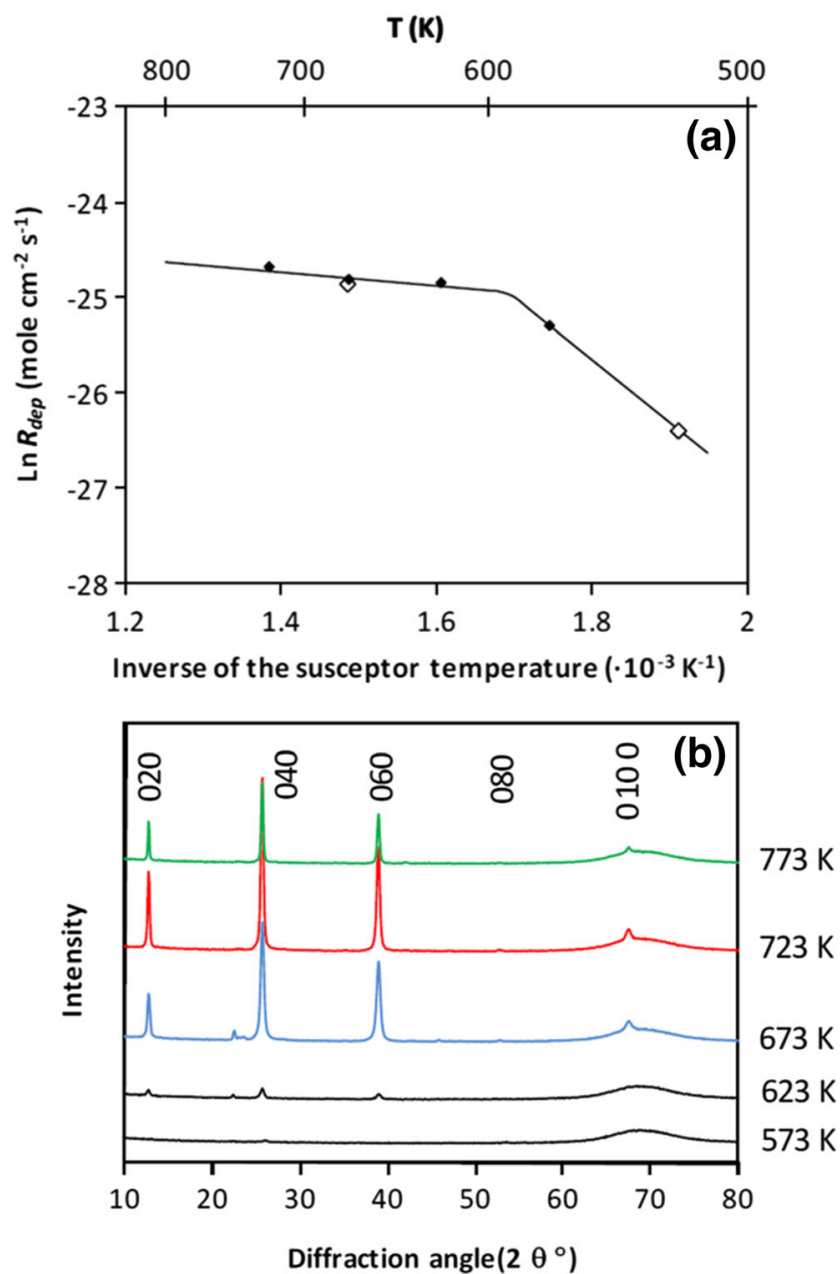

Fig. 9 Arrhenius plot based on RBS measurements for the deposition of $\mathrm{MoO}_{3}$ from $\mathrm{Mo}(\mathrm{CO})_{6}$. The closed symbols indicate deposition runs with a $50 \mathrm{sccm}$ oxygen flow rate while the open symbols have a $1 \mathrm{sccm}$ oxygen supply (a). Corresponding XRD patterns of $\mathrm{MoO}_{3}$ deposited at various temperatures (b). Reproduced with permission from ref. [52] 
Fig. 5(b) and confirms the high irreversible capacity occurring in the first cycle.

\subsection{Anode materials}

In conventional solid-state Li-ion batteries, the negative electrode commonly consists of metallic Li. However, the highly volatile nature and low melting temperature $\left(\sim 181{ }^{\circ} \mathrm{C}\right)$ of metallic $\mathrm{Li}$ is a drawback, restricting large scale utilization of these batteries in micro-electronics applications. The development of novel anode materials with a high specific energy is therefore a prerequisite.

$\mathrm{Li}_{4} \mathrm{Ti}_{5} \mathrm{O}_{12}$ is an interesting alternative for metallic $\mathrm{Li}$ due to high structural stability (zero-strain insertion material) during cycling and a mid-discharge potential close to $1.55 \mathrm{~V}$, which excludes the formation of a Solid Electrolyte Interface (SEI). Many deposition methods have been applied to synthesize $\mathrm{Li}_{4} \mathrm{Ti}_{5} \mathrm{O}_{12}$ film anodes, including sol-gel [62, 63], magnetron sputtering [64, 65], spray pyrolysis [66], aerosol [67] and CVD [68].

MOCVD was used to study the feasibility of depositing $\mathrm{Li}_{4} \mathrm{Ti}_{5} \mathrm{O}_{12}$ thin film anodes with titanium isoproxide (TTIP) and t-BuLi as precursors [69]. Fig. 6(a) shows the XRD patterns of the $\mathrm{Li}_{4} \mathrm{Ti}_{5} \mathrm{O}_{12}$ thin films deposited at $500{ }^{\circ} \mathrm{C}$ with different $\mathrm{Li}$-precursor flow rate. Various t-BuLi flow rates in the range of 100 to $400 \mathrm{sccm}$ were applied with $1 \mathrm{sccm}$ oxygen flow rate and $200 \mathrm{sccm}$ TTIP. It was found that when the tBuLi flow rates are lower than $200 \mathrm{sccm}$ the films consists of two chemical compositions $\left(\mathrm{Li}_{4} \mathrm{Ti}_{5} \mathrm{O}_{12}\right.$ and $\mathrm{TiO}_{2}$ ), due to the deficient amount of $\mathrm{Li}$-precursor to efficiently react with TTIP. Increasing the t-BuLi flow rate to $300 \mathrm{sccm}$ will lead to a pure $\mathrm{Li}_{4} \mathrm{Ti}_{5} \mathrm{O}_{12}$ phase. Galvanostatic (dis)charging reveals the influence on the voltage profiles for the various electrodes in Fig. 6(b). For the electrodes deposited with 100 and $200 \mathrm{sccm} \mathrm{t}$ $\mathrm{BuLi}$, two charging plateaus can be found at 1.55 and $1.91 \mathrm{~V}$, which correspond to the characteristic delithiation plateaus of $\mathrm{Li}_{4} \mathrm{Ti}_{5} \mathrm{O}_{12}$ and $\mathrm{TiO}_{2}$, respectively. The electrodes deposited with a high Li-precursor concentration, only reveal the typical single voltage plateaus. These results agree well with the XRD observations of Fig. 6(a). However, further increasing the Liprecursor to $400 \mathrm{sccm}$ will decrease the storage capacity, which may be due to the potentially introduced Licontaining impurities. Owing to the low quantities, these cannot be detected in the XRD patterns.

The storage capacity obtained with the pure MOCVD deposited $\mathrm{Li}_{4} \mathrm{Ti}_{5} \mathrm{O}_{12}$ sample ( $\left.\mathrm{Li}-300\right)$ is a bit lower than for those electrodes prepared by sol-gel [62], ALD [70]

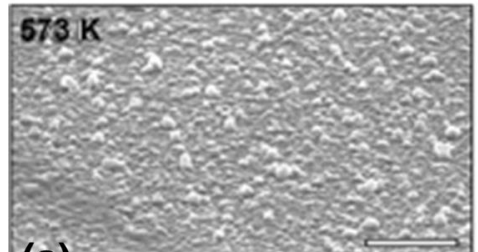

(a)
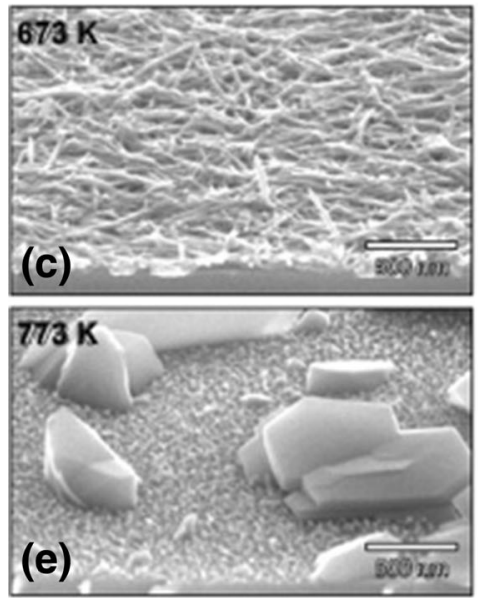
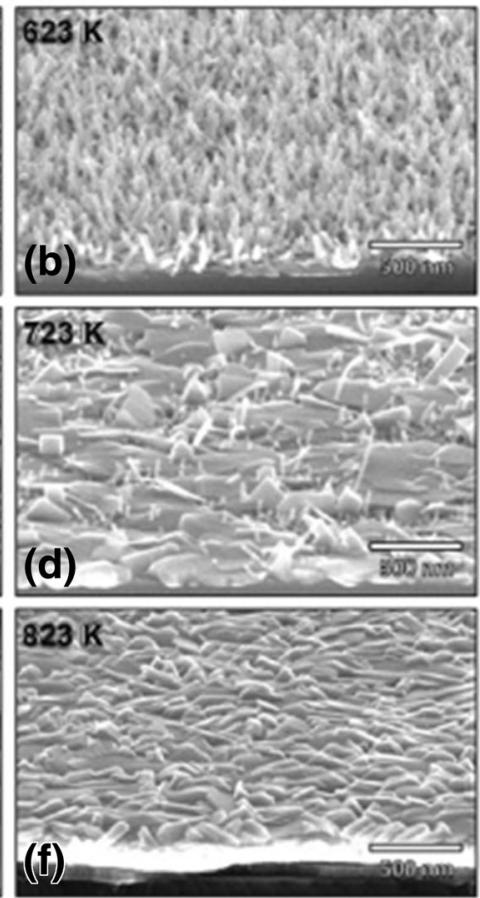

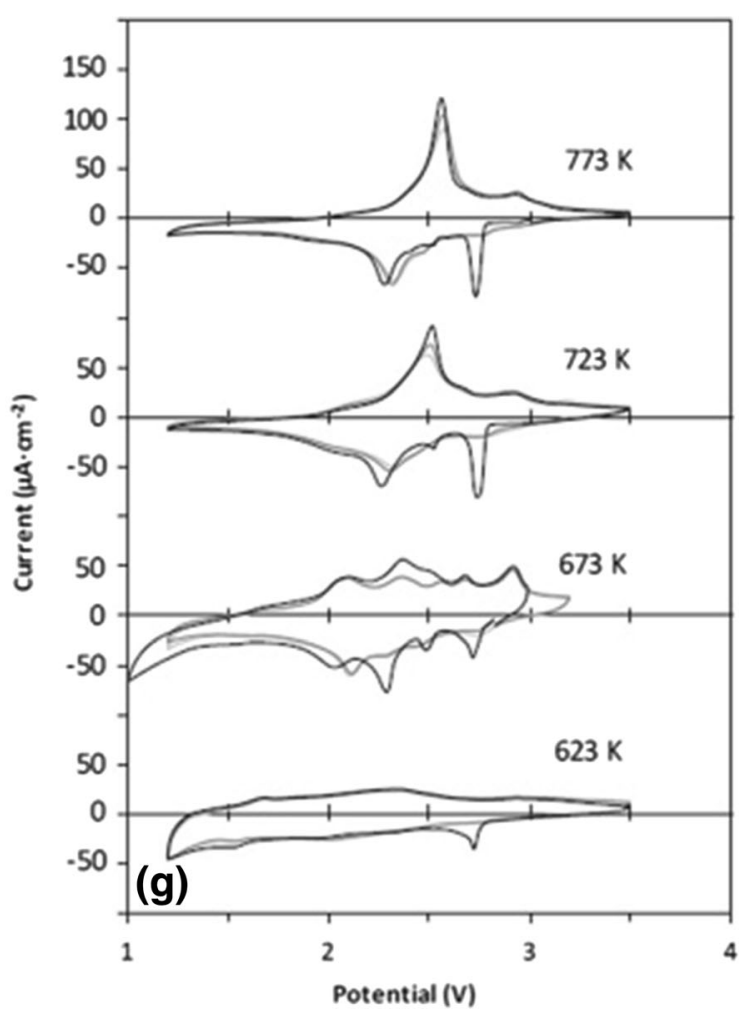

Fig. 10 SEM-images (a-f) and corresponding CV curves $(\mathbf{g})$ of $\mathrm{MoO}_{3}$ samples deposited in the temperature range of 573-773 K. Reproduced with permission from ref. [52] 
and solid-state reaction [71]. This may be attributed to the low deposition temperature $\left(500{ }^{\circ} \mathrm{C}\right)$ and that the samples are not well crystalized. To investigate this, an annealing treatment at $800{ }^{\circ} \mathrm{C}$ for 15 min under $\mathrm{Ar}$ gas was carried out for the Li-300 MOCVD deposited sample. The XRD patterns confirmed the crystallinity was indeed improving after annealing as the intensity of the diffraction peaks of $\mathrm{Li}_{4} \mathrm{Ti}_{5} \mathrm{O}_{12}$ increased significantly (see Fig. 7(a)). The (dis)charging voltage and CV profiles and the corresponding derivative storage capacities are shown in Fig. 7(b-c) and also demonstrate the favorable influence of the improved crystal structure the electrochemical performance, which matches well with that of the characteristic $\mathrm{Li}_{4} \mathrm{Ti}_{5} \mathrm{O}_{12}$ electrodes. After post annealing, the storage capacity was also increased due to the increased number of (de)lithiation sites, induced by the temperature treatment.

$\mathrm{TiO}_{2}$ is an attractive anode material for Li-ion batteries due to the SEI inhibition during (de)lithiation potential above of voltage of $1.5 \mathrm{~V}$. However, bulk-type $\mathrm{TiO}_{2}$ has a poor conductivity and a low Li-ion diffusion rate, limiting the rate capability and storage capacity. Some thin film formation methods have been reported to deposit $\mathrm{TiO}_{2}$, for example, by sputter deposition [72], ALD [73], CVD [74] and liquid phase deposition [75]. Forming thin film-based electrodes is a promising route to address the conductivity issue also by MOCVD [76]. Figure $8(\mathrm{a}-\mathrm{d})$ shows SEM images of MOCVD deposited $\mathrm{TiO}_{2}$ films at various temperatures. It was found that all films are homogeneous without showing any cracks or pinholes. It is interesting to note that all the samples deposited in this temperature range show a high degree of crystallinity. The Raman spectra of the deposited films are shown in Fig. 8e as a function of deposition temperature and reveal that the deposited films have the typical anatase $\mathrm{TiO}_{2}$ structure. The deposition rate increases at higher temperatures as the Arrhenius plot shows in Fig. 8(f). The two slopes indicate a kinetically controlled deposition reaction rate at low temperatures and a diffusion controlled mechanism at higher temperatures.

$\mathrm{MoO}_{3}$ is another interesting electrode material, which can be used both as anode or cathode in Li-ion batteries due to the medium (dis)charging voltage range in the range of 2.5 to $3.0 \mathrm{~V}$. This material can be lithiated to $\mathrm{Li}_{1.5} \mathrm{MoO}_{3}$, resulting in a $100 \%$ volume expansion [77] To address such a volume change during (dis)charging, some porous $\mathrm{MoO}_{3}$ materials were synthesized [78]. Some thin film-based $\mathrm{MoO}_{3}$ deposition reports have been presented in the field of CVD [79], Sol-gel [80], ion beam [80], sputter deposition [81] and ALD [82]. $\mathrm{MoO}_{3}$ has been deposited by means of MOCVD to investigate the possibility to deposit thin films, using
$\mathrm{Mo}(\mathrm{CO})_{6}$ as Mo-precursor [52]. Temperature and oxygen dependencies has been investigated in the MOCVD deposition process. Figure 9(a) shows the Arrhenius plot based on RBS analyses of the deposition rate as a function of temperature with an oxygen flow of 1 and 50 sccm. It can be observed that there are again two growth rate regimes in the investigated temperature range. The deposition rate is diffusion controlled at temperatures higher than $580 \mathrm{~K}$ and kinetically controlled at
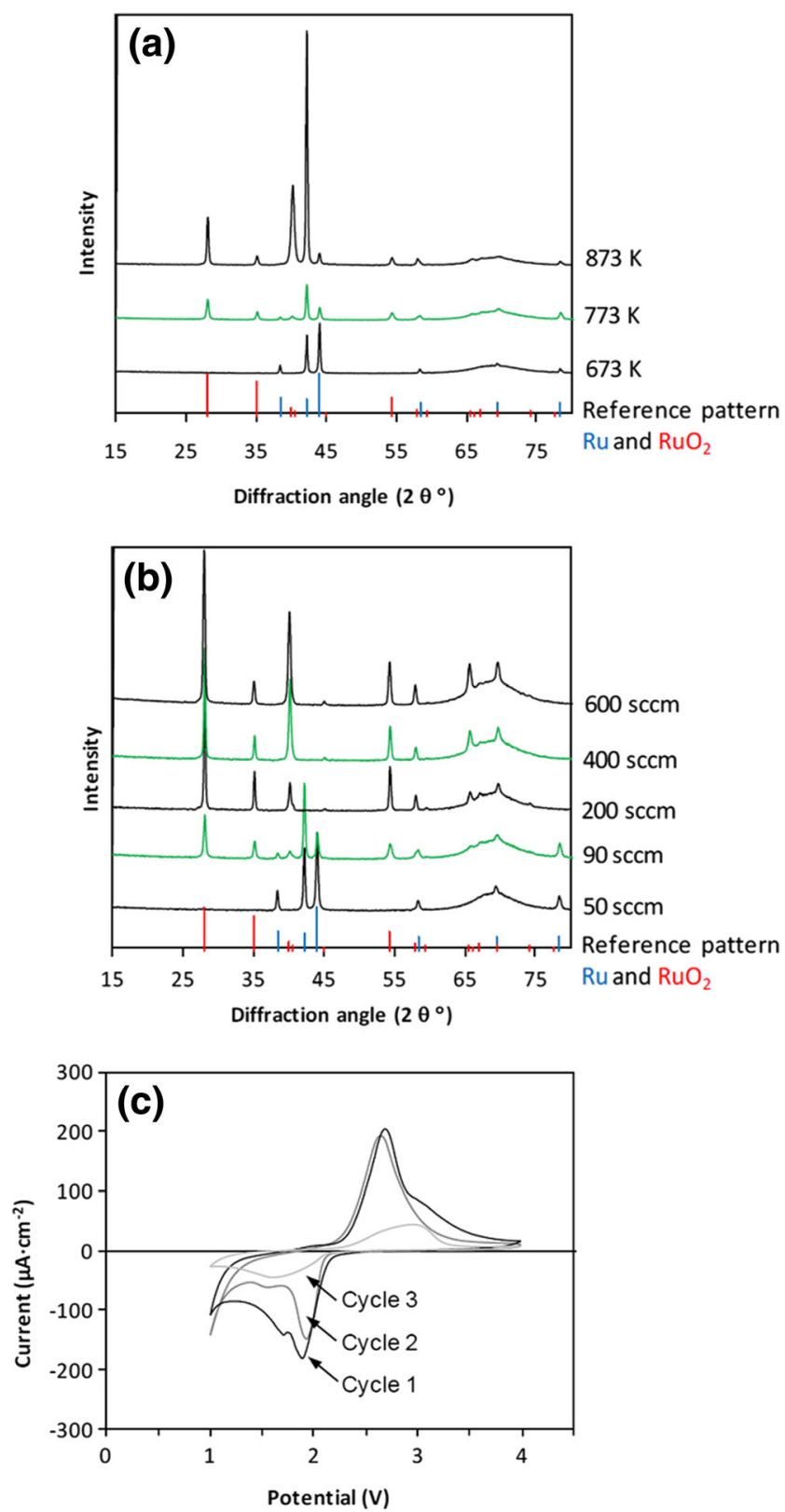

Fig. 11 X-ray diffraction patterns of ruthenium(oxide) deposited at three temperatures with fixed oxygen flow rate of $90 \mathrm{sccm}$ (a) and deposited under various oxygen flow rates at a fixed temperature of $773 \mathrm{~K}(\mathbf{b})$ and $\mathrm{CV}$ investigation $\left(1 \mathrm{mV} \cdot \mathrm{s}^{-1}\right)$ of $\mathrm{RuO}_{2}$ deposited at $773 \mathrm{~K}$ with a $400 \mathrm{sccm}$ $\mathrm{O}_{2}$ flow (c). Reproduced with permission from ref. [52] 
Fig. 12 SEM images of tilt view of a $30 \mu \mathrm{m}$ wide trench (a); crosssection view of a $10 \mu \mathrm{m}$ wide trench (b); top (c) and crosssection view (d) of a 3D pillar substrate. Reproduced with permission [76]. Copyright 2016, The Electrochemical Society

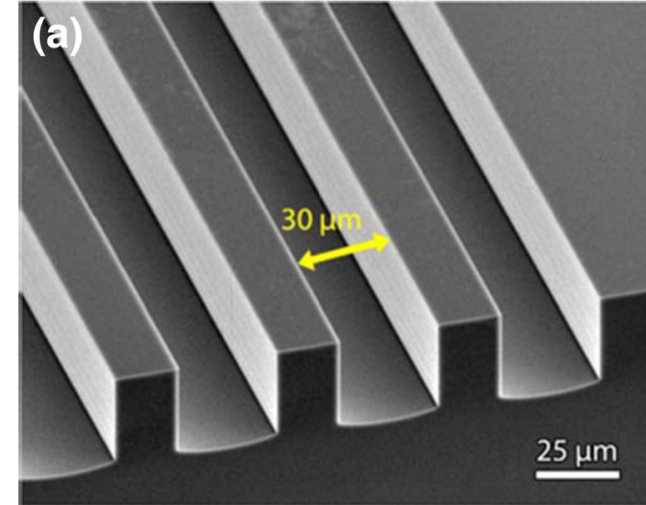

(b)

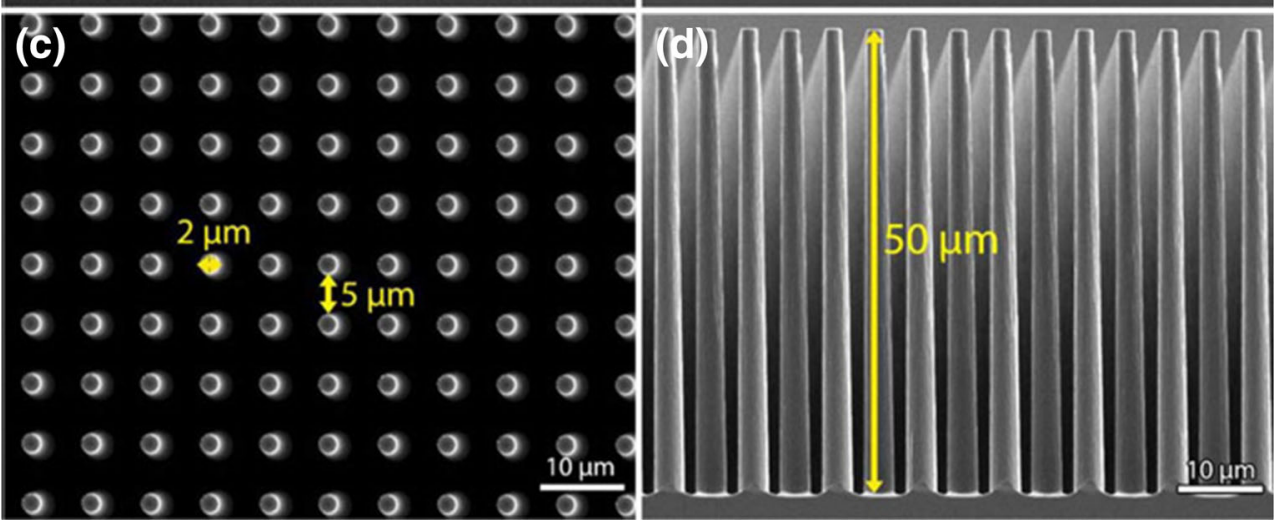

lower temperatures. When using different oxygen flow rates, the deposition rates are overlapping, suggesting that there is no significant influence of the oxygen content in this concentration range.
The XRD spectra are shown in Fig. 9(b) and indicate that there a clear correlation between the deposition temperature and the crystallinity of $\mathrm{MoO}_{3}$. The films are in amorphous state at temperatures lower than
Fig. $13 \mathrm{Li}_{3} \mathrm{PO}_{4}$ thin film morphology deposited at $300{ }^{\circ} \mathrm{C}$ for $6 \mathrm{~h}$ inside a $30 \mu \mathrm{m}$ wide trench (a) and at higher magnification at the top (b), the center (c) and bottom (d). Reproduced with permission [47]. Copyright 2015, The Electrochemical Society
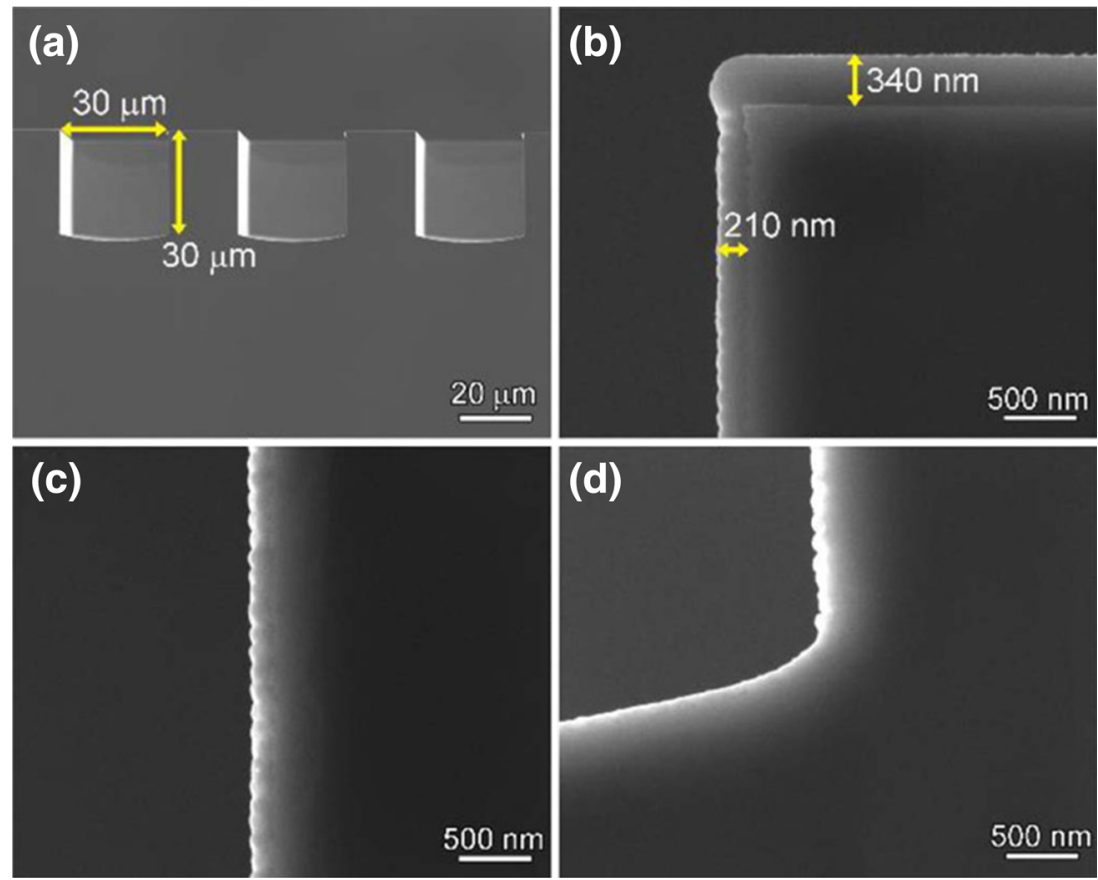
$573 \mathrm{~K}$ and the crystallinity increases at more elevated deposition temperatures. The samples are completely crystalline at temperatures higher than $673 \mathrm{~K}$. However, SEM images show that the deposited films have an interesting 3D morphology and even present nanorods or nanowire structures (see Fig. 10(a-f)). Results of electrochemical stability measurements in the deposition temperature range of 623 to $773 \mathrm{~K}$ are shown in Fig. $10(\mathrm{~g})$. The CV plots of electrodes deposited at lower temperatures (623 and $673 \mathrm{~K}$ ) display reveal very broad voltage characteristics. For the films deposited at higher temperatures $(723$ and $773 \mathrm{~K}$ ), the responses are much better. After the first cycle the electrodes much more in line to what is electrochemical expected.

$\mathrm{RuO}_{2}$ has a high electronic conductivity and is therefore often used as current collector. However, only a few papers were reporting on using this material in all-solid-state LIBs $[83,84] . \mathrm{RuO}_{2}$ is considered to be a conversion electrode with respect to Li-ions. The (de)lithiation reaction has been represented by [83]

$4 \mathrm{Li}^{+}+\mathrm{RuO} \mathrm{O}_{2}+4 e^{-} \leftrightarrow 2 \mathrm{Li}_{2} \mathrm{O}+\mathrm{Ru}$

The possibility of employing MOCVD to deposit $\mathrm{RuO}_{2}$ electrodes for all-solid-state LIBs has also been investigated, using (iButylCp) ${ }_{2} \mathrm{Ru}$ as Ru-precursor [52]. During the MOCVD deposition, the temperature was varied in the range of 673 to $873 \mathrm{~K}$ using a fixed oxygen flow rate of $90 \mathrm{sccm}$. Figure 11(a) shows the measured XRD patterns, revealing a positive effect of the temperature on the crystalline of $\mathrm{RuO}_{2}$. At $673 \mathrm{~K}$, $\mathrm{RuO}_{2}$ has been detected together with some small amounts of metallic $\mathrm{Ru}$. Increasing the deposition temperature to $773 \mathrm{~K}$ the amount of $\mathrm{RuO}_{2}$ increases and a single phase $\mathrm{RuO}_{2}$ has been formed at $873 \mathrm{~K}$. The oxygen flow rate also plays a significant role in the composition of the deposited films. Figure 11(b) shows the XRD patterns of the samples deposited at $773 \mathrm{~K}$ with various flow rates in the range of 50 to $600 \mathrm{sccm}$. It clearly shows that increasing oxygen amount during deposition improves the crystallinity of the $\mathrm{RuO}_{2}$ thin films. The sample deposited at $773 \mathrm{~K}$ at an oxygen flow rate of $400 \mathrm{sccm}$ was used for the electrochemical test. The $\mathrm{CV}$ were measured at $1 \mathrm{mV} / \mathrm{s}$ between 1 and $4 \mathrm{~V}$ (see Fig. 11(c)). It shows that the current density decreases sharply upon cycling and the maximum current at the third cycle is only $25 \%$ of the value in the initial cycle. This $\mathrm{RuO}_{2}$ electrode fading can be attributed to the large volume expansion (about 100\%) during (de)lithiation [83, 85], leading to continuously losing active material into the liquid electrolyte. The poor cycling stability challenges the deposited $\mathrm{RuO}_{2}$ films to become high performance anode materials. Further modification of the deposited $\mathrm{RuO}_{2}$ is needed to improve the cycling performance.

\section{3D thin film deposition for all-solid-state Li-ion batteries}

It can be concluded that thin film based all-solid-state LIBs are strong candidates to power numerous wireless autonomous devices. It is, however, impossible to disassemble integrated devices to charge these batteries. The power and energy performance are two other main characteristics of these on-board batteries, especially for medical implants. However, for conventional twodimensional (2D) all-solid-state (planar) LIBs it is
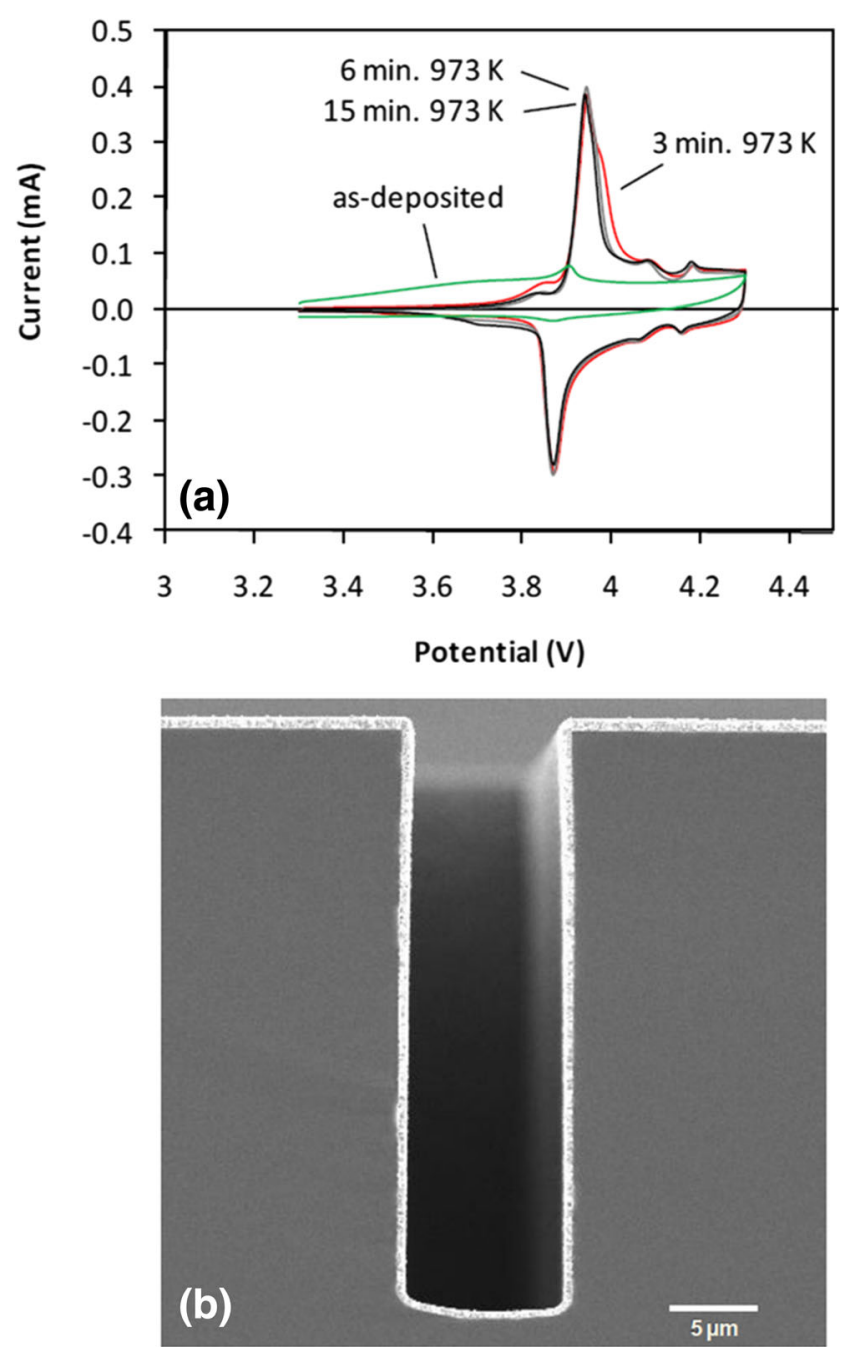

Fig. $14 \mathrm{CV}$ curves of $\mathrm{LiCoO}_{2}$ measured at $1 \mathrm{mV} \cdot \mathrm{s}^{-1}$ annealed at $973 \mathrm{~K}$ for 3, 6 or $15 \mathrm{~min}$ are compared with the as-deposited film (a) and SEM image of a $\mathrm{LiCoO}_{2}$ thin film deposited for $8 \mathrm{~h}$ in a trench that is $10 \mu \mathrm{m}$ wide and $30 \mu \mathrm{m}$ deep (b). Reproduced with permission from ref. [52] 
complicated to combine a high power with high energy performance due to the limited chip area and volume. To obtain high storage capacities, two routes can be followed: One approach is to enlarge the chip area of 2D all-solid-state LIBs, but this is not compatible with the small nature of integrated devices; another way is to increase the thickness of the battery electrodes, which would cause greatly increased diffusion pathways for Li-ions, limiting the power performance.

Considering these limitations new architectures are proposed, which are all based on the exploration of the third dimensional (3D) geometry. An advantage of $3 \mathrm{D}$ batteries is that the internal surface area between cathode, electrolyte and anode is enlarged, which means that with almost the same amount of packaging and substrate material, much higher currents can be obtained and consequently creating high power batteries. Compared with planar solid-state batteries, the 3D allsolid-state LIB concept simultaneously improves the volumetric storage capacity and rate capability.

To investigate the electrochemical performance of 3D batteries, the films should be homogeneously deposited onto 3D structured substrates. Well-known 3D substrates are nano-rod templates [86, 87], carbon micro-rod arrays [88], aerogel architectures [89, 90], microchannel Plates [91, 92], etched pillars [69] and trenches [47, 52], and each of these morphologies have its own advantages and disadvantages. Among them the etched pillars and trenches are the two frequently-used structures due to their well-defined aspect-ratio (enlarged surface area) and good mechanical properties. Figure 12 shows typical pillar- and trench-structured substrates. The surface enlargement factor $(A)$ of the pillar substrate has been calculated, according to

$A=1+\pi \mathrm{dh} /(d+l)^{2}$

where $\mathrm{d}, \mathrm{h}$ and 1 represent the diameter, depth and distance between Si pillars, respectively [11]. For trench substrates $A$ can be represented by

$A=1+2 d(l-s) / l(w+s)$

in which $\mathrm{d}$ is the trench depth, $\mathrm{w}$ the width, $\mathrm{s}$ is the spacing between the trenches and $\mathrm{L}$ is the total footprint length of the battery structure. As an advanced technique for depositing thin film materials, MOCVD can also be used to achieve step-conformal and homogeneous deposits in the highly structured substrates, offering good opportunities to create $3 \mathrm{D}$ all-solid-state batteries. It is important to recognize that the usable area is limited for small electronic devices. So, the traditional performance indicators of batteries, namely the gravimetric and volumetric energy and power densities are less relevant. Instead, the real issue is how much energy and power a device can deliver per footprint area, measured in terms of $\mathrm{mAh} \cdot \mathrm{cm}^{-2}, \mathrm{~J} \cdot \mathrm{cm}^{-2}, \mu \mathrm{W} \cdot \mathrm{mm}^{-2}$, etc [93].

Based on, for example, the observation made in Fig. 1 it was concluded that the deposition of $\mathrm{Li}_{3} \mathrm{PO}_{4}$ in the temperature range from 300 to $500{ }^{\circ} \mathrm{C}$ is
Fig. 15 Configuration of the 3D substrate for layer uniformity analysis (a), deposited $\mathrm{Li}_{4} \mathrm{Ti}_{5} \mathrm{O}_{12}$ film on the top (b), middle (c) and bottom (d) of a 3D trench. Reproduced with permission [69]. Copyright 2016, Elsevier
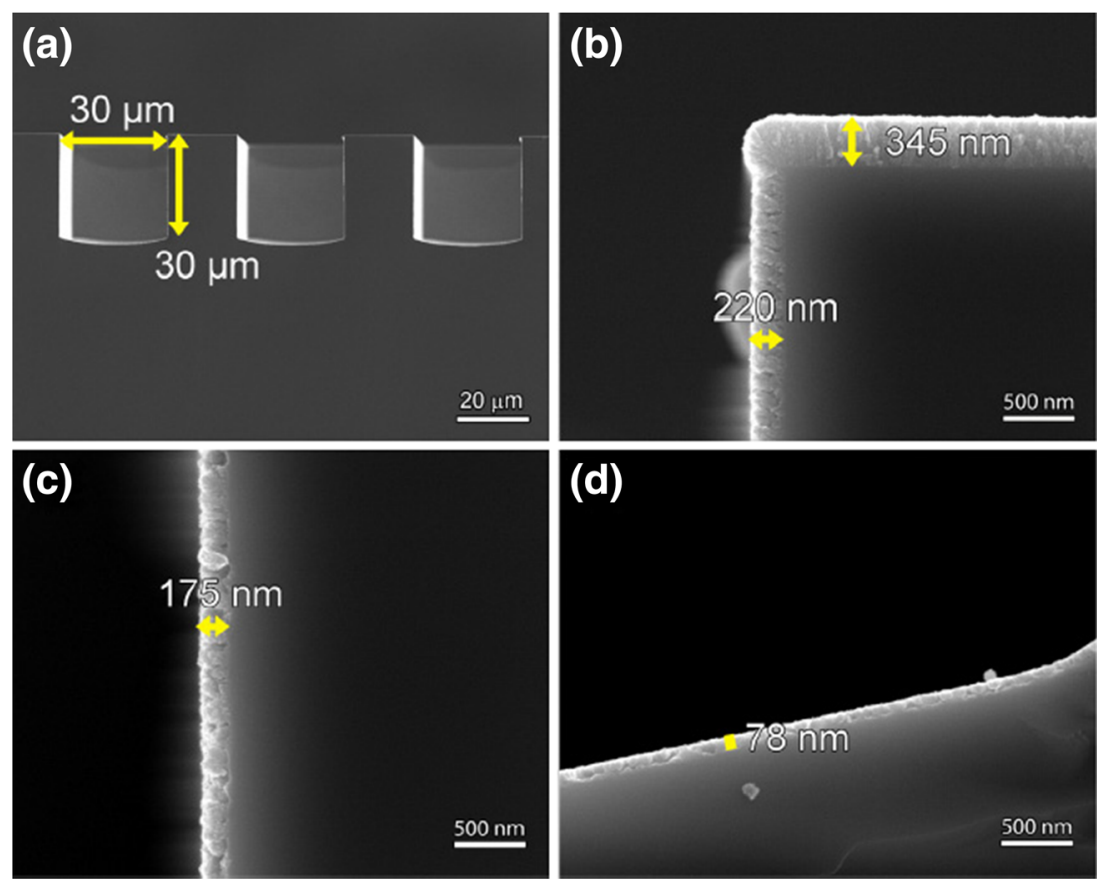
diffusion-controlled [47]. In order to achieve a homogeneous deposition in 3D structured substrates, the samples should be deposited at a kinetically controlled condition. This implies that the temperatures should be reduced to even lower values. However, the deposition temperatures should still be high enough for the reaction to occur under these conditions. Therefore the lowest temperature of $300{ }^{\circ} \mathrm{C}$ was chosen to investigate the $3 \mathrm{D}$ deposition of $\mathrm{Li}_{3} \mathrm{PO}_{4}$. Figure 13 shows MOCVDdeposited $\mathrm{Li}_{3} \mathrm{PO}_{4}$ thin films in $30 \mu \mathrm{m}$ wide and deep trenches for $6 \mathrm{~h}$. It shows an as-expected continuous and homogeneous thickness of about $340 \mathrm{~nm}$ thin film on top of the trenches. Moving into the trench, the film thickness starts to deviate from the top part and a thickness of $210 \mathrm{~nm}$ film was only deposited at the topcorner of the trench. The film thickness is even further reduced at the bottom, down to about $60 \mathrm{~nm}$.

As described in section 2.1, high temperature $\mathrm{LiCoO}_{2}$ is beneficial to obtain electrochemical active thin films to be applied as cathode. However, according to the result shown in Fig. 3(c-f), depositing $\mathrm{LiCoO}_{2}$ at lower temperatures can give more homogeneous films, which is good to achieve a conformal 3D geometry. These are therefore contradictory characteristics. To solve these conflicting aspects, new studies have been carried out to evaluate the $3 \mathrm{D}$ deposition possibility at low-temperatures, followed by a high-temperature annealing step to obtain electrochemically active layers [52]. In an attempt to investigate this $\mathrm{LiCoO}_{2}$ was first deposited at $673 \mathrm{~K}$ for $2 \mathrm{~h}$ and, subsequently, annealed at $973 \mathrm{~K}$ for different time, i.e. 3, 6, 15 and $30 \mathrm{~min}$. The electrochemical stability of the deposited and annealed planar samples are shown in Fig. 14(a). It was found that there is no large difference between of the different annealing times, indicating that the crystalline transformation is rather rapid and $3 \mathrm{~min}$ is already sufficient for this conversion. Figure 14(b) shows the homogeneity of the deposited film in a 10 by $30 \mu \mathrm{m}$ trench. This illustrates that $\mathrm{LiCoO} 2$ can be successfully deposited with a good step coverage of over $80 \%$.

It has been shown that $\mathrm{Li}_{4} \mathrm{Ti}_{5} \mathrm{O}_{12}$, an interesting anode material, can also be deposited in 3D by MOCVD. Figure 15 presents the SEM images of the deposited films at $500{ }^{\circ} \mathrm{C}$ and post-annealing at $800{ }^{\circ} \mathrm{C}$ into a 30 by $30 \mu \mathrm{m}$ trench. As a result, an aspect ratio of $23 \%$ was obtained at the bottom part of the trench. To check the electrochemical performance, the TiN coated silicon pillars substrates were used, of which the pillars have a height of $50 \mu \mathrm{m}$, a diameter of $2 \mu \mathrm{m}$ at a distance of $5 \mu \mathrm{m}$ (Fig. 16a) [69]. As shown in Fig. 16b, the 3D pillar electrode can deliver an improved storage capacity per foot print in comparison to planar electrodes. This is a bit lower than the theoretical
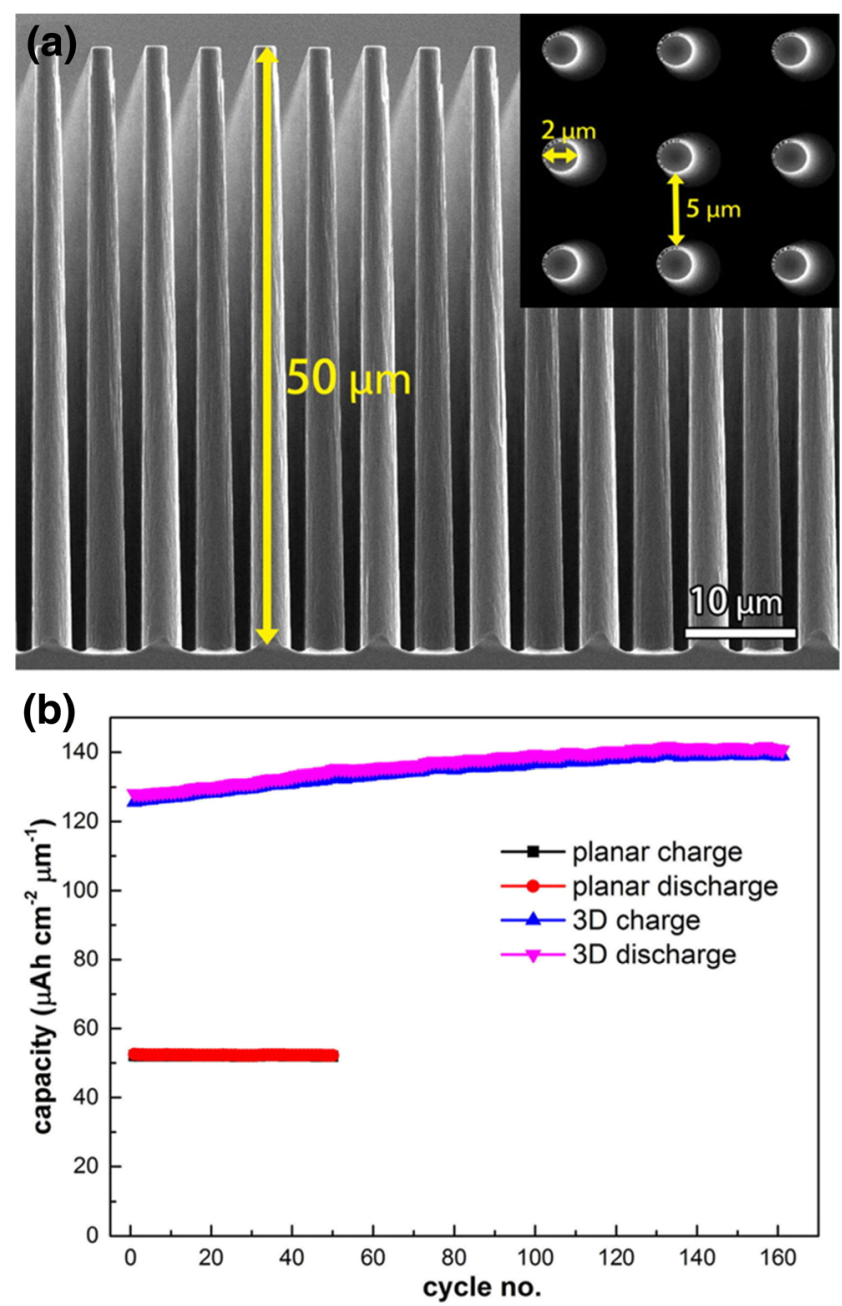

Fig. 16 Cross-section view of the 3D substrate used for electrochemical measurements, inset image is the top-view (a), electrochemical performances of $\mathrm{Li}_{4} \mathrm{Ti}_{5} \mathrm{O}_{12}$ anodes deposited on a planar and $3 \mathrm{D}$ substrate (b). Reproduced with permission [69]. Copyright 2016, Elsevier

surface area enlargement of the pillar substrates of about 7.5. This has been attributed to the inhomogeneous film coverage in the bottom of the $3 \mathrm{D}$ architecture. Interestingly it was concluded that the storage capacity of the 3D electrode is increasing during cycling, which has been attributed to some gas trapping at the bottom and liquid electrolyte penetration into the pillars upon cycling [69].

The MOCVD deposition characteristics of $\mathrm{TiO}_{2}$ in 3D has also been reported [76]. To get a homogeneous coverage in $3 \mathrm{D}$ structured substrates, the $\mathrm{TiO}_{2}$ films were deposited at $350{ }^{\circ} \mathrm{C}$. Figure 17 shows the SEM images of deposited $\mathrm{TiO}_{2}$ into a pillar-structured substrate, using TiN as current collector. In comparison to $\mathrm{Li}_{4} \mathrm{Ti}_{5} \mathrm{O}_{12}, \mathrm{TiO}_{2}$ can remarkably be deposited with a high aspect ratio of about $94 \%$, much higher than that of $\mathrm{Li}_{4} \mathrm{Ti}_{5} \mathrm{O}_{12}$. This is due to the fact that a separate $\mathrm{Li}$ 
Fig. 17 Tilt view of 3D pillar substrates covered by $\mathrm{TiO}_{2}(\mathbf{a})$, SEM images of deposited $\mathrm{TiO}_{2}$ film on top (b), surface (c) and bottom (d) part of a 3D pillar substrate. The deposition temperature is $350^{\circ} \mathrm{C}$.

Reproduced with permission [76].

Copyright 2016, The

Electrochemical Society
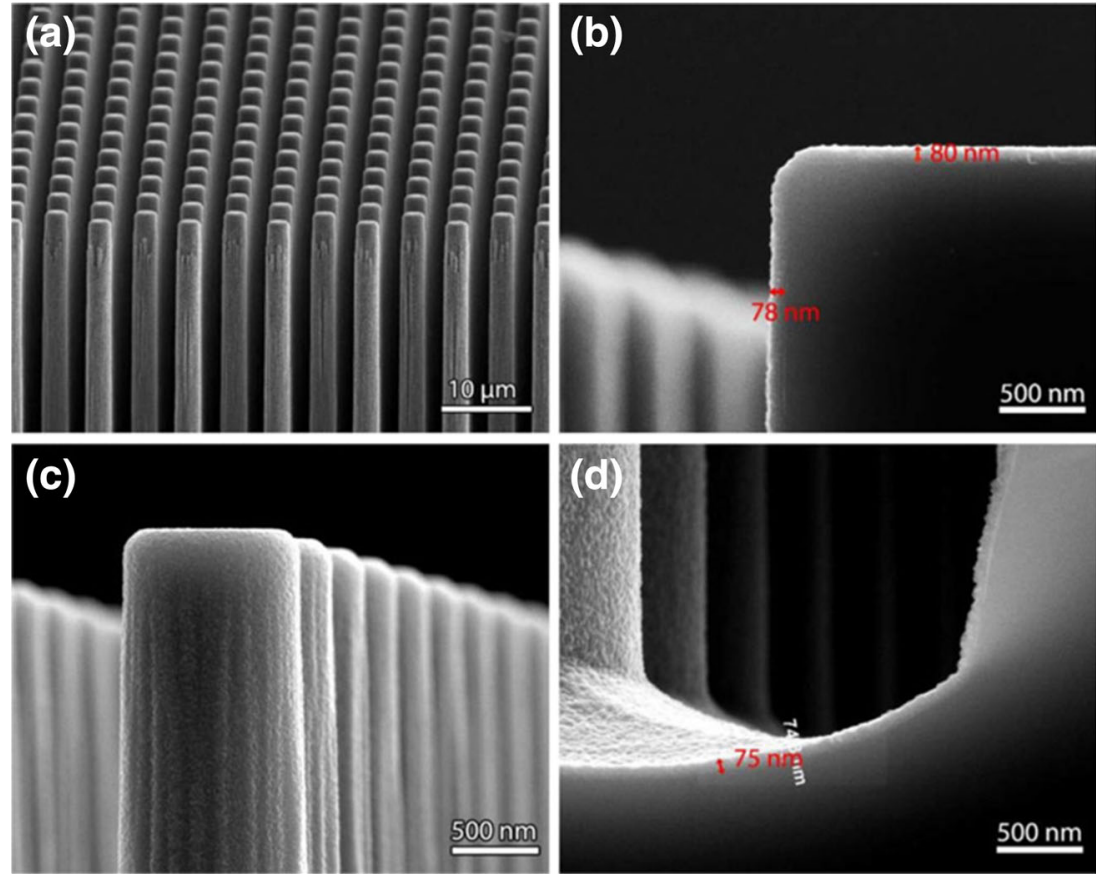

precursor is not involved, which leads to a more simple collision and reflection during the MOCVD deposition process. As shown in Fig. 18 the $3 \mathrm{D} \mathrm{TiO}_{2}$ electrodes clearly exhibits an improved storage capacity and power performance in comparison to planar electrodes. Obviously, the 3D electrode geometry exhibits lower over-potentials, especially under high current loading conditions, indicating the improved power performance. Also, in line with the author's expectations the 3D electrode shows much higher storage capacities at all current densities than the planar electrode (see Fig. 18(c)). Figure 18(d) shows the areal capacity improvement of the $3 \mathrm{D} \mathrm{TiO}_{2}$ over a planar electrode. It is worthwhile to note that the increase is more significant at higher current densities and can even reach a factor of 16 at $80 \mu \mathrm{A} / \mathrm{cm}^{-2}$. This value is higher than the theoretical surface enlargement of 7.5, which manifests the advantage of the 3D electrode geometry in improving both the power and energy density performance.

\section{Concluding remarks and outlook}

Based on the above analysis, it can be concluded that MOCVD is an advanced technique to deposit thin film based materials for application in all-solid-state LIBs. During deposition, the applied parameters, including temperature, precursor flow and post-annealing, will influence the formed films' quality, like surface morphology, composition, electrochemical stability and storage capacity. High performance electrode and electrolyte materials have been deposited. With optimized parameters, MOCVD can be employed further for depositing homogeneous film in highly structured substrates to for 3D all-solid-state LIBs. The obtained 3D electrodes show an improved power and energy performance over the planar electrodes.

In spite of the present promising results, some challenging issues still remain and should be addressed in the coming future: (i) The price and toxicity of precursors used in the MOCVD processes might limit the applicability in commercial devices. Novel and cheap precursor materials are therefore in urgent need to be developed. (ii) Some electrode materials deposited show less promising cycling performance, such as $\mathrm{RuO}_{2}$. This is due to the fact that the electrochemical results are all obtained in liquid electrolyte systems. The construction of full all-solid-state LiBs could be more beneficial in this respect as the stability of the applied electrode materials are less sensitive in these cases. (iii) The present thin film materials are mainly belonging to the group of oxide materials. New classes of composite materials, such sulfides and selenides, could be the next generation of materials for all-solid-state LIBs. (iv) Homogeneous and high-aspect ratio deposition is the leading property to enable the feasibility of $3 \mathrm{D}$ allsolid-state LIBs. Therefore new MOCVD deposition strategies are of great interest. For example, introducing 

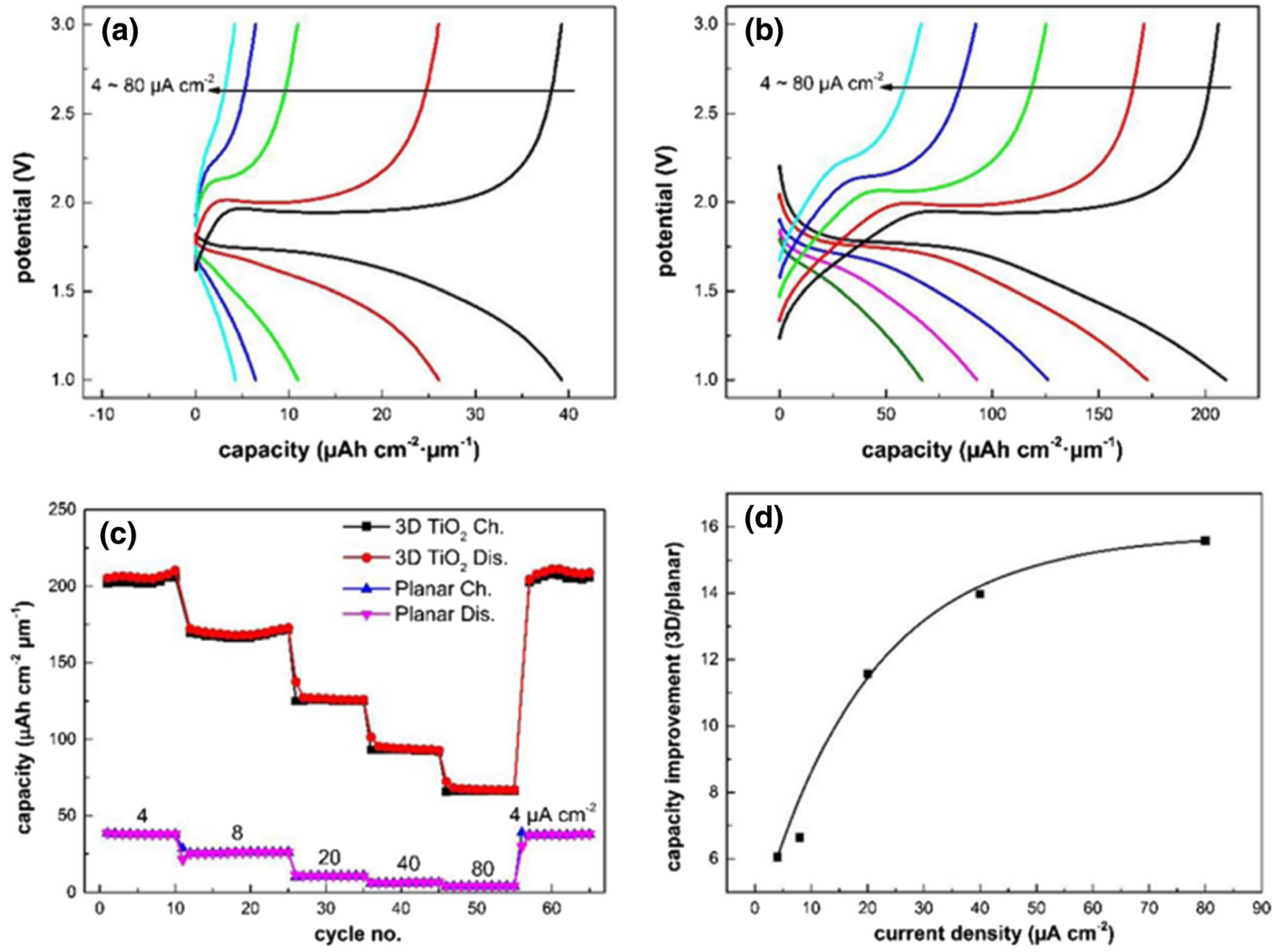

Fig. 18 Voltage curves of planar $\mathrm{TiO}_{2}(\mathbf{a})$ and $3 \mathrm{D} \mathrm{TiO}_{2}$ electrodes (b); Areal capacity of planar and $3 \mathrm{D} \mathrm{TiO}_{2}$ electrodes for charging $(\mathrm{Ch})$ and discharging (Dis) at different current densities (c); areal capacity

turbulent substrate holder systems or micro-blowing systems, facilitating perpendicular precursor diffusion seems to be promising.

In conclusion, it is to be expected that together with the increased interest from industry that the development of both advanced MOCVD deposition technologies and new high performance battery materials will facilitate the development of 3D-integrated all-solid-state Lithium ion batteries.

Acknowledgements C. Chen would like to thank the Chinese Scholarship Council (CSC) for financially supporting the work described in this paper.

Open Access This article is distributed under the terms of the Creative Commons Attribution 4.0 International License (http:// creativecommons.org/licenses/by/4.0/), which permits unrestricted use, distribution, and reproduction in any medium, provided you give appropriate credit to the original author(s) and the source, provide a link to the Creative Commons license, and indicate if changes were made.

improvement as a function of current densities (d). Reproduced with permission [76]. Copyright 2016, The Electrochemical Society

\section{References}

1. P.H.L. Notten, F. Roozeboom, R.A.H. Niessen, L. Baggetto, Adv. Mater. 19, 4564 (2007)

2. M. Armand, J.M. Tarascon, Nature 451, 652 (2008)

3. J.M. Tarascon, M. Armand, Nature 414, 359 (2001)

4. L. Baggetto, H.C.M. Knoops, R.A.H. Niessen, W.M.M. Kessels, P.H.L. Notten, J. Mater. Chem. 20, 3703 (2010)

5. K. Brandt, Solid State Ionics 69, 173 (1994)

6. C.A. Vincent, Solid State Ionics 134, 159 (2000)

7. L. Baggetto, R.A.H. Niessen, F. Roozeboom, P.H.L. Notten, Adv. Funct. Mater. 18, 1 (2008)

8. B. Scrosati, J. Appl. Electrochem. 2, 231 (1972)

9. X.B. Meng, X.Q. Yang, X.L. Sun, Adv. Mater. 24, 3589 (2012)

10. M. Knez, K. Nielsch, L. Niinistö, Adv. Mater. 19, 3425 (2007)

11. J.F.M. Oudenhoven, L. Baggetto, P.H.L. Notten, Adv. Energy Mater. 1, 10 (2011)

12. J.Y. Song, Y.Y. Wang, C.C. Wan, J. Power Sources 77, 183 (1999)

13. A.D. Robertson, A.R. West, A.G. Ritchie, Solid State Ionics 104, 1 (1997)

14. H. Li, Z.X. Wang, L.Q. Chen, X.J. Huang, Adv. Mater. 21, 4593 (2009) 
15. W.J. Zhang, J. Power Sources 196, 13 (2011)

16. V.V. Kharton, F.M.B. Marques, A. Atkinson, Solid State Ionics 174, 135 (2004)

17. T. Minami, A. Hayashi, M. Tatsumisago, Solid State Ionics 177, $2715(2006)$

18. J. Janek, W.G. Zeier, Nature Energy (2016). doi:10.1038/ NENERGY.2016.141

19. A. Hayashi, T. Ohtomo, F. Mizuno, K. Tadanaga, M. Tatsumisago, Electrochem. Commun. 5, 701 (2003)

20. V. Thangadurai, S. Narayanan, D. Pinzaru, Chem. Soc. Rev. 43, 4714 (2014)

21. Z.C. Liu, W.J. Fu, E.A. Payzant, X. Yu, Z.L. Wu, N.J. Dudney, J. Kiggans, K.L. Hong, A.J. Rondinone, C.D. Liang, J. Am. Chem. Soc. 135, 975 (2013)

22. K. Homma, M. Yonemura, T. Kobayashi, M. Nagao, M. Hirayama, R. Kanno, Solid State Ionics 182, 53 (2011)

23. K. Minami, A. Hayashi, M. Tatsumisago, J. Am. Ceram. Soc. 94, 1779 (2011)

24. D. Wohlmuth, V. Epp, M. Wilkening, Chem. Phys. Chem. 16, 2582 (2015)

25. Y. Onodera, K. Mori, T. Otomo, M. Sugiyama, T. Fukunaga, J. Phys. Soc. Jpn. 81, 044802 (2012)

26. N. Kamaya, K. Homma, Y. Yamakawa, M. Hirayama, R. Kanno, M. Yonemura, T. Kamiyama, Y. Kato, S. Hama, K. Kawamoto, A. Mitsui, Nat. Mater. 10, 682 (2011)

27. Y.F. Mo, S. Ping Ong, G. Cede, Chem. Mater. 24, 15 (2012)

28. D.A. Weber, A. Senyshyn, K.S. Weldert, S. Wenzel, W.B. Zhang, R. Kaiser, S. Berendts, J. Janek, W.G. Zeier, Chem. Mater. 28, 5905 (2016)

29. A. Manuel Stephan, K.S. Nahm, Polymer 47, 5952 (2006)

30. J.B. Bates, N.J. Dudney, G.R. Gruzalski, R.A. Zuhr, A. Choudhury, C.F. Luck, J.D. Robertson, Solid State Ionics 53, 647 (1992)

31. H. Aono, E. Sugimoto, Y. Sadaoka, N. Imanaka, G. Adachi, J. Electrochem. Soc. 137, 1023 (1990)

32. F. Vereda, N. Clay, A. Gerouki, R.B. Goldner, T. Haas, P. Zerigian, J. Power Sources 89, 201 (2000)

33. G. Perentzis, E.E. Horopanitis, E. Pavlidou, L. Papadimitriou, Mater. Sci. Eng. B 108, 174 (2004)

34. Z.Y. Li, X.F. Chen, X.F. Hu, J. Phys. D 29, 2740 (1996)

35. S. Ohta, K. Tetsuro, T. Asaoka, J. Power Sources 196, 3342 (2011)

36. R. Murugan, V. Thangadurai, W. Weppner, Angew. Chem. Int. Ed. 46, 7778 (2007)

37. V. Thangadurai, W. Weppner, J. Power Sources 142, 339 (2005)

38. P. Knauth, Solid State Ionics 180, 911 (2009)

39. K. Takada, Acta Mater. 61, 759 (2013)

40. X.H. Yu, J.B. Bates, G.E. Jellison, F.X. Hart, J. Electrochem. Soc. 144, 524 (1997)

41. K. Naoaki, I. Naoya, M. Yasutaka, T. Yoshinari, J. Kawamura, ECS Trans. 16, 53 (2009)

42. S. Yuki, A. Dials, A. Hayashi, M. Tatsumisago, Solid State Ionics 182, 59 (2011)

43. B.Q. Wang, J. Liu, Q. Sun, R.Y. Li, T.-K. Sham, X.L. Sun, Nanotechnology 25, 504007 (2014)

44. W.Y. Liu, Z.W. Fu, C.L. Li, Q.Z. Qin, Electrochem. Solid State Lett. 7, J36 (2004)

45. H.Y. Park, S.C. Nam, Y.C. Lim, K.G. Choi, K.C. Lee, G.B. Park, S.R. Lee, H.P. Kim, S.B. Cho, J. Electroceram. 17, 1023 (2006)

46. N. Kuwata, N. Iwagami, Y. Tanji, Y. Matsuda, J. Kawamura, J. Electrochem. Soc. 157, A521 (2010)

47. J. Xie, J.F.M. Oudenhoven, P.R.M.L. Harks, D.J. Li, P.H.L. Notten, J. Electrochem. Soc. 162, A249 (2015)

48. T.A. Deis, P.P. Phule, J. Mater. Sci. Lett. 11, 1353 (1992)

49. J.A. Agostinelli, G.H. Braunstein, T.N. Blanton, Appl. Phys. Lett. 63, $123(1993)$

50. J. Liu, M.N. Banis, X.F. Li, A. Lushington, M. Cai, R.Y. Li, T.-K. Sham, X.L. Sun, J. Phys. Chem. C. 117, 20260 (2013)
51. Y. Saito, T. Shiosaki, Jpn. J. Appl. Phys. I. 30, 2204 (1991)

52. J. F. M. Oudenhoven, PhD thesis Eindhoven University of Technology (2011), ISBN: 978-90-386-2870-7

53. W.D. Johnston, R.R. Heikes, D. Sestrich, J. Phys. Chem. Solids 7, 1 (1958)

54. Y.H. Rho, K. Kanamura, J. Electrochem. Soc. 151, A1406 (2004)

55. T. Matsushita, K. Dokko, K. Kanamura, J. Electrochem. Soc. 152, A2229 (2005)

56. J.B. Bates, N.J. Dudney, B.J. Neudecker, F.X. Hart, H.P. Jun, S.A. Hackney, J. Electrochem. Soc. 59, 147 (2000)

57. P.J. Bouwman, B.A. Boukamp, H.J.M. Bouwmeester, H.J. Wondergem, P.H.L. Notten, J. Electrochem. Soc. 148, A311 (2001)

58. J.F.M. Oudenhoven, T. van Dongen, R.A.H. Niessen, M.H.J.M. de Croon, P.H.L. Notten, J. Electrochem. Soc. 156, D169 (2009)

59. Y.S. Jung, A.S. Cavanagh, A.C. Dillon, M.D. Groner, S.M. George, S-H Lee. J. Electrochem. Soc. 151, A75 (2010)

60. M.M. Thackeray, S.D. Baker, K.T. Adendorff, J.B. Goodenough, Solid State Ionics 17, 175 (1985)

61. Z.-W. Fu, Y. Wang, Y. Zhang, Q.-Z. Qin, Solid State Ionics 170, 105 (2004)

62. Y.H. Rho, K. Kanamura, M. Fujisaki, J. Hamagami, S. Suda, T. Umegaki, Solid State Ionics 151, 151 (2002)

63. L. Kavan, M. Gratzel, Electrochem. Solid-State Lett. 5, A39 (2002)

64. C.L. Wang, Y.C. Liao, F.C. Hsu, N.H. Tai, M.K. Wu, J. Electrochem. Soc. 152, A653 (2005)

65. F. Wunde, F. Berkemeier, G. Schmitz, J. Power Sources 215, 109 (2012)

66. Y. Yu, J.L. Shui, C.H. Chen, Solid State Commun. 135, 485 (2005)

67. R. Inada, K. Shibukawa, C. Masada, Y. Nakanishi, Y. Sakurai, J. Power Sources 253, 181 (2014)

68. K. Tadanaga, A. Yamaguchi, A. Hayashi, M. Tatsumisago, J. Mosa, M. Aparicio, J. Asian Ceram. Soc. 3, 88 (2015)

69. J. Xie, P.R.M.L. Harks, D.J. Li, L.H.J. Raijmakers, P.H.L. Notten, Solid State Ionics 287, 83 (2016)

70. X. Meng, J. Liu, X. Li, M.N. Banis, J. Yang, R. Li, X. Sun, RSC Adv. 3, 7285 (2013)

71. X. Li, M.Z. Qu, Z.L. Yu, Solid State Ionics 181, 635 (2010)

72. M. Kitano, K. Funatsu, M. Matsuoka, M. Ueshima, M. Anpo, J. Phys. Chem. B 110, 25266 (2006)

73. B.J. Choi, D.S. Jeong, S.K. Kim, C. Rohde, S. Choi, J.H. Oh, H.J. Kim, C.S. Hwang, K. Szot, R. Waser, B. Reichenberg, S. Tiedke, J. Appl. Phys. 98, 033715 (2005)

74. W.G. Lee, S.I. Woo, J.C. Kim, S.H. Choi, K.H. Oh, Thin Solid Films 237, 105 (1994)

75. J.-G. Yu, H.-G. Yu, B. Cheng, X.-J. Zhao, J.C. Yu, W.-K. Ho, J. Phys. Chem. B 107, 13871 (2003)

76. J. Xie, J.F.M. Oudenhoven, D.J. Li, C.G. Chen, R.-A. Eichel, P.H.L. Notten, J. Electrochem. Soc. 163, A2385 (2016)

77. T. Tsumura, M. Inagaki, Solid State Ionics 104, 183 (1997)

78. Y.G. Li, B. Tan, Y.Y. Wu, Nano Lett. 8, 265 (2008)

79. A. Donnadieu, D. Davazoglou, A. Abdellaoui, Thin Solid Films 164, 333 (1988)

80. A.K. Prasad, D.J. Kubinski, P.I. Gouma, Sensors Actuators B 93, $25(2003)$

81. T.J. Vink, R.G.F.A. Verbeek, J.H.M. Snijders, Y. Tamminga, J. Appl. Phys. 87, 7252 (2000)

82. M. Diskus, O. Nilsen, H. Fjellvåg, J. Mater. Chem. 21, 705 (2011)

83. P. Balaya, H. Li, L. Kienle, J. Maier, Adv. Funct. Mater. 13, 621 (2003)

84. E.G. Keith, C.K. Alexander, X.Y. Chen, A.S. Marshall, N. Malachi, A.Y. Cao, L.B. Hu, W.R. Gary, ACS Nano 9, 464 (2015)

85. O. Delmer, P. Balaya, L. Kienle, J. Maier, Adv. Mater. 20, 501 (2008)

86. E. Perre, L. Nyholm, T. Gustafsson, P.L. Taberna, P. Simon, K. Edstrom, Electrochem. Commun. 10, 1467 (2008) 
87. S. Leopold, I.U. Schuchert, J. Lu, M.E. Toimil Molares, M. Herranen, J.O. Carlsson, Electrochim. Acta 47, 4393 (2002)

88. C.L. Wang, G.Y. Jia, L.H. Taherabadi, M.J. Madou, J. Microelectromech. Syst. 14, 348 (2005)

89. J.W. Long, D.R. Rolison, Acc. Chem. Res. 40, 854 (2007)

90. D.R. Rolison, R.W. Long, J.C. Lytle, A.E. Fischer, C.P. Rhodes, T.M. McEvoy, M.E. Bourga, A.M. Lubers, Chem. Soc. Rev. 38, $226(2009)$
91. D. Golodnitsky, M. Nathan, V. Yufit, E. Strauss, K. Freedman, L. Burstein, A. Gladkich, E. Peled, Solid State Ionics 177, 2811 (2006)

92. M. Nathan, D. Golodnitsky, V. Yufit, E. Strauss, T. Ripenbein, I. Shechtman, S. Menkin, E. Peled, J. Microelectromech. Syst. 14, 879 (2005)

93. Y. Wang, B. Liu, Q. Li, S. Cartmell, S. Ferrara, Z.D. Deng, J. Xiao, J. Power Sources 286, 330 (2015) 